\title{
ICT intelligent support solutions toward the reduction of heating demand in cold and mild European climate conditions
}

\author{
Francesco Reda - Daniela Pasini • Ari Laitinen • \\ Teemu Vesanen
}

Received: 28 December 2017 / Accepted: 28 October 2018 /Published online: 28 November 2018

(C) The Author(s) 2018

\begin{abstract}
Adopting intelligent solutions in residential buildings for reducing the HVAC energy demand, especially during the operational stages, is becoming more popular. Information and Communication Technology (ICT) devices are often the backbone of such intelligent solutions, since they can enable an easy and intuitive bidirectional communication between energy systems and users and, at the same time, are able to suggest energy saving procedures. These energy saving procedures are mainly suggested when energy hungry behaviors are registered. Particularly, authors of this paper have assumed setting indoor set point temperatures, adjusting ventilation airflow rates and opening windows as energy hungry behaviors to tackle by means of ICT-driven intelligent solutions. Two different localities, namely Helsinki and Milan, have been considered as representative of cold and mild European climate conditions.

Results report that adopting ICT-driven intelligent solutions for setting heating setback and indoor set point temperatures and for controlling the mechanical ventilation according to actual people's presence and $\mathrm{CO}_{2}$ levels ensures consistent reductions of energy demand, especially in Helsinki, where mechanical ventilation is adopted. Moreover, if mechanical ventilation does not
\end{abstract}

F. Reda $(\bowtie) \cdot$ A. Laitinen $\cdot T$. Vesanen

VTT Technical Research Centre of Finland Ltd., P.O. Box 1000, 02044 Espoo, Finland

e-mail: francesco.reda@vtt.fi

\section{Pasini}

Department of Architecture, Built Environment and Construction Engineering, Politecnico di Milano, Via Ponzio 31, 20133 Milan, Italy work properly or is missing, benefits in reducing energy demand can be even achieved by adopting ICT-driven intelligent solutions for advising building users when windows should be opened or closed according to sensed $\mathrm{CO}_{2}$ levels. This is relevant especially in Milan. The adoption of intelligent HVAC-window controls, which enable to turn off the HVAC when windows are opened, does not ensure a significant effect in Helsinki. Instead, this solution is promising in Milan, especially when heating systems with low thermal masses are installed.

Keywords Energy saving scenarios · Energy hungry behaviors · Applied ICT solutions · HVAC control · Opening windows

\section{Introduction}

EU member states are concretely aiming at a clean energy future, setting very ambitious and binding targets for the year 2030, overcoming the 2010/31/EU directive ("Briefing EU Legislation in Progress Improving energy performance of buildings Proposal for a Directive of the European Parliament and of the Council amending Directive 2010/31/EU on the energy performance of buildings" 2017). In accordance with the aforementioned directive, each member state has to comply from the year 2020 with energy efficiency targets ("2020 climate and energy package-European Commission" 2017): $20 \%$ cut in greenhouse gas emissions (from 1990 levels), $20 \%$ produced energy from renewables, and $20 \%$ improvement in energy efficiency. This represents 
the beginning of an imminent transition from fossil fuelbased energy systems toward green energy systems. Moreover, member states are committed to have more than $27 \%$ share of energy consumption coming from renewable sources, about $40 \%$ reduction of greenhouse gas emissions compared to 1990's levels and more than $27 \%$ energy savings compared with the business-asusual scenario by 2030 ("2030 Energy StrategyEuropean Commission" 2017). Lately, a great step forward has been achieved with the COP21 agreement signed by 195 countries in Paris in 2015. This gave enough trust to EU and other countries to adopt tighter climate targets. Indeed, COP21 agreement was partially the reason behind the 2030 EU energy targets ("Paris Agreement-European Commission” 2015).

One of the most energy hungry sectors in Europe is the residential, accounting for around $25 \%$ of the final energy consumption (Eurostat 2012). During the operational stages, buildings do not consume energy themselves. Instead, occupants, doing everyday life activities, determine how energy is used in buildings. Sometimes, their behaviors generate excessive and/or unwanted energy use (Pasini et al. 2017; Reda et al. 2017). These are referred as to energy hungry behaviors. Energy hungry behaviors can be turned into energy rational behaviors with the support of intelligent Information and Communication Technology (ICT)-driven solutions. These are promising tools for both creating awareness of energy usage and stimulating energy saving practices, finally turning energy hungry behaviors into energy rational behaviors.

European Commission is giving substantial trust to ICT solutions for achieving energy savings in buildings issuing set of official documents (European Commission 2014, 2016). As demonstrated in many projects (e.g., Hannus et al. 2010; "ICT 4 E2B Forum" 2017), ICT can be instrumental in obtaining more efficient energy use as regards design and operational stages of buildings, addressing also occupant behaviors ("CORDIS Archive: European Commission: ICT for Sustainable Growth: Projects" 2015, "Energy Efficient Buildings. ICT for Sustainable Growth. EuropaInformation Society" 2017). Aligned with a previous research, potential energy savings can be generated by using different ICT solutions, meant for tackling specific energy hungry behaviors. In particular, a solution, comprising simple and non-intrusive sensors connected to a visual platform for translating sensors physical measures into easily accessible and understandable information, can be provided to users as a successful vehicle for tackling people energy hungry behaviors and promoting behavioral changes (Pasini et al. 2017).

Within this paper, different scenarios have been simulated for estimating the impact of such hungry behaviors on building energy demand (space heating and ventilation) and for outlining the benefits of such ICTdriven intelligent solutions. The effects of different HVAC operating control modes in two European climate conditions, referring to the cities of Helsinki and Milan, have been considered.

Advanced energy simulations have been carried out for performing the analyses. Energy simulation is, indeed, considered a reliable and powerful assessment tool before building real prototypes. In fact, energy simulation has often been used for comparing building energy system solutions: from different envelope elements (Reda et al. 2015a) to various energy system components (Reda et al. 2015b) and/or operating strategies (Reda and Laitinen 2015).

It is well known that there is usually a gap between simulated and measured consumptions (McCoy et al. 2018; De Wilde 2014). There are multiple reasons for the gap, e.g., errors in using the simulations software and inaccuracies in modeling the building and its systems. However, simulation and modeling software tool are widely utilized for assessing the impact of people behaviors on energy consumption (Delzendeh et al. 2017). The results of simulations allow highlighting benefits of ICT-driven intelligent solutions in reducing the heating demand.

The first part of the paper discusses the main energy hungry behaviors of people and HVAC control modes. The second section describes the methodology of the research. The case study is presented in the third section, and the results have been discussed in the fourth section. Finally, the paper ends with concise conclusions.

\section{Literature review}

There is a great evidence that reducing energy demand for space heating is a challenging task not only related to the technical performance of a building but also strongly related to occupant behaviors (D'Oca et al. 2014). In fact, occupant can perform (Fabi et al. 2012):

- Changes that alter the living environment thermal conditions improving comfort conditions (e.g., adjusting indoor set point temperature) 
- Changes for making occupants comfortable to the sensed conditions, adapting occupants to the surrounding environment (e.g., adjusting clothing)

- Actions that indirectly affect the indoor environment by modifying internal heat gains or energy use (e.g., having a shower)

Depending on occupants' activities, these changes or actions reduce or increase energy consumptions. Hence, occupant behavior is often cited as the most important reason for the performance gap between predicted and actual energy performance of buildings (De Wilde 2014; D'Oca et al. 2015). Moreover, models for simulating occupant behaviors greatly depend on the building context. Adopted models vary from stochastic to deterministic, and recently, they are also applied with statistical analysis for evaluating the accuracy of models (Yan and Hong 2018). However, considering the complexity of the topic for considering occupant influence on building conditions, a branch of research is still under development.

When excessive and/or unwanted energy uses occur, energy hungry behaviors realize. Among several energy hungry behaviors, improperly setting of indoor set point temperatures and/or airflow rates and opening windows have been identified as relevant actions responsible for energy waste in residential and office buildings. These considerations have been outlined according to literature (Cetin et al. 2014; Fabi et al. 2013; Fournier and Leduc 2014; Gunay et al. 2016; Karjalainen 2007, 2016; Pasini et al. 2017; Wang and Greenberg 2015; Wang et al. 2017; Yan and Hong 2018) and in line with real behaviors monitored on Finnish residential buildings. The first two behaviors refer to HVAC control actions, while the second represents people actions. Thus, as regards people actions, improper people behaviors of opening windows and setting HVAC operations have been assessed. In order to give a more profound understanding of these two aspects to the reader, authors have further discussed opening window behaviors and HVAC control modes in the next paragraphs.

\section{Window opening behaviors}

Window opening behaviors greatly affect building energy consumptions. However, the effects of these behaviors depend on the way opening of windows is managed (Fig. 1).

In some buildings, windows are never opened because they are sealed or not operable or because of particular people attitude. This particular condition has been considered for defining the base case in the analyses.

However, windows are generally opened because of specific people behaviors or according to particular indoor conditions.

Indeed, occupants mainly open windows because of concerns about health effects of poor indoor conditions and for achieving satisfactory indoor comfort conditions in case of overheating when external conditions allow (Karjalainen 2016). This behavior is not based on perception or past experiences, but rather on knowledge and education. Controlling the opening of windows is usually done manually, meaning that people decide when to open or close windows based on a number of aspects: physiological (e.g., age and gender), psychological (e.g., preference in terms of temperature), social (e.g., presence), physical or environmental (e.g., outdoor and indoor temperature, $\mathrm{CO}_{2}$ concentration), and contextual (e.g., window type, season, time of day) (Fabi et al. 2012). Window opening behavior is often connected to everyday life activities occurring at specific times along the day (Jeong et al. 2016). Particularly, actions of cooking, cleaning, and getting fresh air account respectively for $27 \%, 40 \%$, and $33 \%$ of total openings (Jeong et al. 2016). In general, it has been proved that occupants open the windows for a fixed period at the same time every day, regardless of the environmental conditions (Rune Vinther Andersen 2009). Thus, in order to simplify the definition of people behaviors in opening windows, authors have assumed that windows are opened for a certain time before occupants leave their home (in the morning) and after they get in (in the evening).

Besides the manual actions of people for opening and closing windows, ICT-driven intelligent solutions can potentially support people managing the opening of windows through advanced controls based on specific sensed levels of indoor conditions, as $\mathrm{CO}_{2}$ concentration. In these cases, off-the-shelf ICT solutions (e.g., Netatmo ("Netatmo 2016)) advise users when high $\mathrm{CO}_{2}$ levels are registered and, consequently, users could manually open windows. Moreover, considering the increment of energy consumptions when windows are opened, besides showing $\mathrm{CO}_{2}$ levels, existing ICT solutions (e.g., Netatmo ("Netatmo 2016) and Kadtronix ("Kadtronix 2016)) can potentially act directly on the HVAC system, turning it off when windows are opened (Syed 2012). 


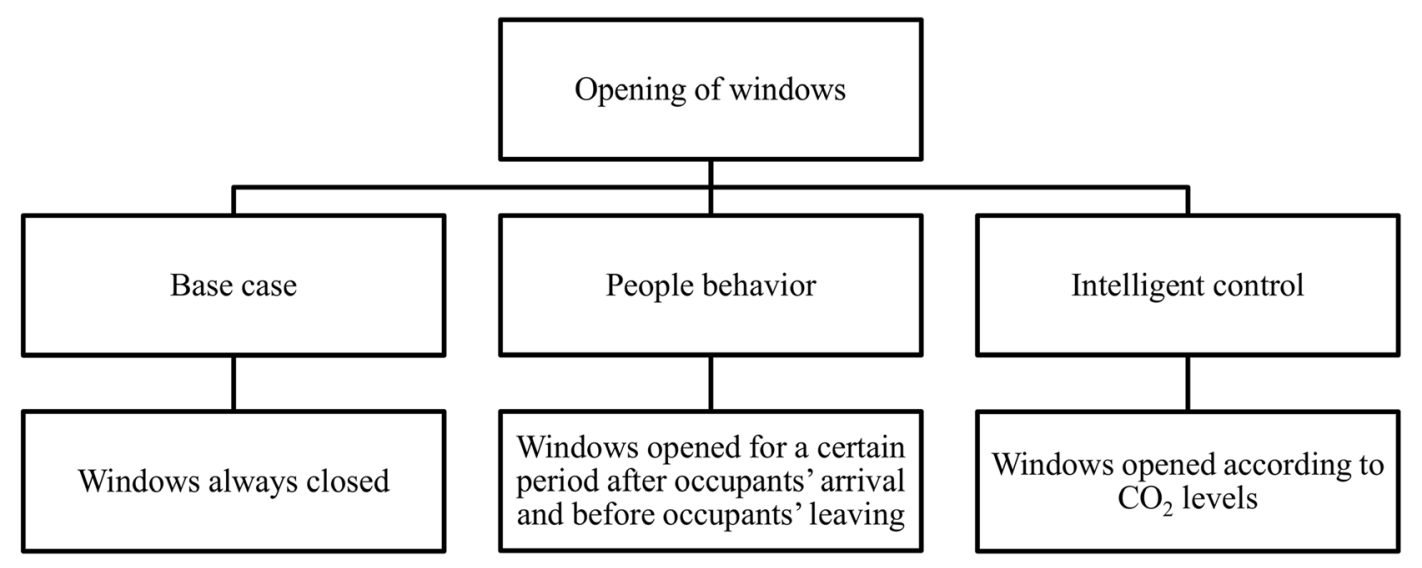

Fig. 1 Scenarios for opening of windows

Considering the consistent energy consumption generally registered in case people open windows for a relatively short time, embracing intelligent control modes of opening windows could lead to a correct management of air change rate and indoor environmental conditions and, consequently, to consistent energy savings. Indeed, depending on indoor and outdoor climate conditions, at the time when the event (opening of windows) realizes, the duration of the period when a window stays open drastically affects the building energy consumption.

Therefore, authors have investigated how intelligent solutions can support the reduction of energy demand, considering different control modes for opening windows and linked HVAC operations (as described in "HVAC control modes"). Particularly, authors have focused on $\mathrm{CO}_{2}$ concentration, as one of the most used indicators for indoor air quality (Chenari et al. 2016; Wang and Wang 2012).

\section{HVAC control modes}

An improper control of HVAC working conditions can drastically increase energy consumption. In particular, for improving the readability of the paper, authors have classified HVAC operating control modes as constant, fixed, and intelligent (Fig. 2).

Whereas static control can be implemented by using ordinary thermostats and ventilation valves in the apartments, fixed control requires some programmability in the system. In the central heating, this would mean a heating control unit that closes the heating during summer time. An intelligent control requires building automation system that gathers the sensor data from the apartments and sets the heating and ventilating systems into correct operating mode.

Constant and fixed control modes act in the same way regardless of the registered conditions in the surrounding environment. As regards constant controls, the status of particular settings is not modified; they remain constant all the time. Therefore, temperature and ventilation set points are constant, while setback temperatures are not implemented. Instead, as regards fixed controls, HVAC operations observe pre-set schedules for both temperature and ventilation set point, implementing also setback settings on both indoor set point temperature and ventilation rates. Both control modes do not punctually control indoor thermal conditions, since they do not take into account the real occupancy status (people's presence). These control modes are not meant to consume as less energy as possible ensuring, at the same time, adequate comfort conditions. People decide when changing actuators' status or setting new schedules according to their preferences.

Instead, intelligent controls tailor HVAC operations in relation with specific surrounding environment conditions. These controls are able to punctually control indoor thermal conditions, considering the real occupancy status. In this case, temperature and ventilation setbacks are controlled based on people's presence or sensed indoor conditions. This control mode is assumed to be done by means of ICT devices.

For what concerns fixed controls, lowering the thermostat temperature and implementing setback procedures when rooms are not occupied can decrease energy consumption. As the influence of pre-programmed temperature set points and setbacks for reducing the heating 


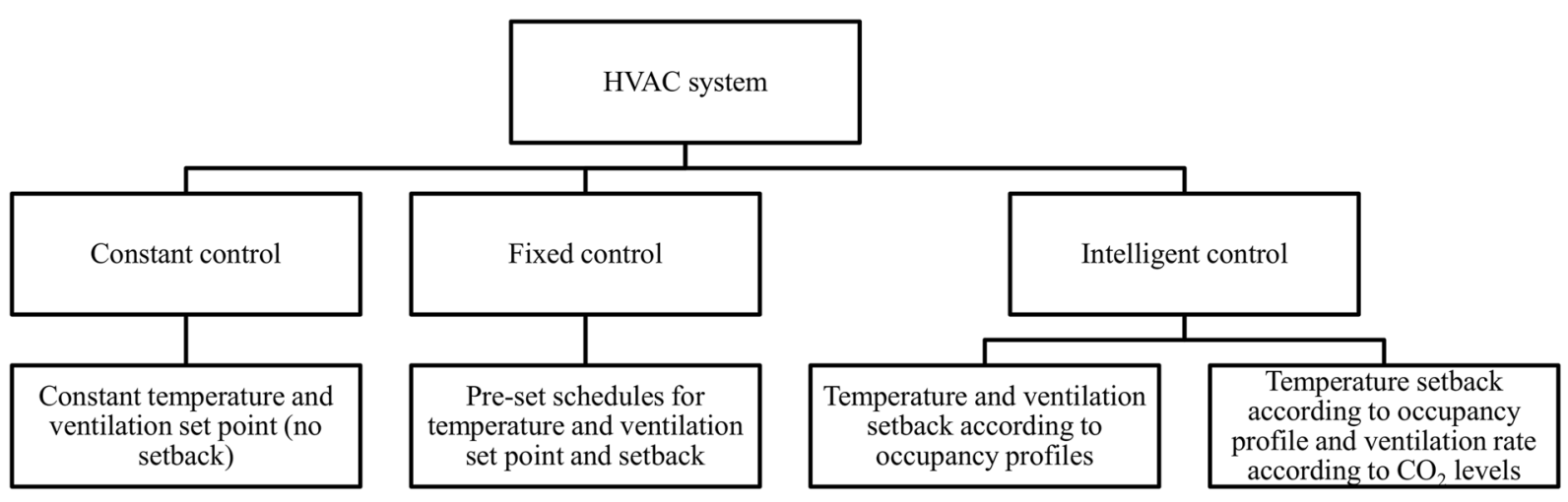

Fig. 2 Solutions for the control of HVAC systems

demand is emerged (Fournier and Leduc 2014), impacts on building energy consumption of setback-to-set point transition time have been estimated. A recent study stated that adopting correct setback-to-set point transition time can potentially realize $30 \%$ reduction in heating and $13 \%$ in cooling loads (Gunay et al. 2016). Thus, since the correct implementation of temperature set points and setbacks brings consistent energy savings, such procedure should be adequately implemented into HVAC operations. Moreover, coupling temperature controls with pre-conditioning of spaces (adjusting setback and set point temperatures and the setback-to-set point transition time) ensures occupant comfort, especially during intermittent building occupancy (Terrill and Rasmussen 2016). Therefore, several solutions have been adopted for a fixed control, e.g., setting daily and weekend setback temperatures in winter and setup temperatures in summer to improve energy performances in offices (Ruivo et al. 2013). Indeed, adequately setting a transition time for pre-heating a building before people get in improves HVAC energy performance, if pre-heating time is not too long (Kleiminger et al. 2014). Fixed optimal transition curves, processing indoor and outdoor thermal conditions, can be used to estimate the transition time for properly shaving HVAC peak loads (Candanedo et al. 2015; Date et al. 2015). However, if people's presence is not considered, the control cannot be defined as intelligent.

Setting such HVAC operations should not be only controlled using a fixed approach, but rather assisted by intelligent technologies, in order to realize consistent energy savings. Indeed, implementing setback and set point temperatures transition time periods as HVAC operations should be supported by an intelligent control mode. To outline potential benefits of people's presence on intelligent controls for setting setback and set point temperatures transition time periods, it has been demonstrated that predicting occupants' movements within the living environment, using contextual information obtained from mobile phones, can decrease building energy consumption by $26 \%$ (Lee et al. 2013). Without interacting with mobile phone data, currently off-theshelf sensors are already able to sense occupancy and sleep patterns in homes. These solutions can be used for rationally operating the HVAC, consequently generating energy savings (Lu et al. 2010). Furthermore, smart thermostats with automatically controlled setback temperatures can reduce building energy consumption during on-peak times (Cetin et al. 2014).

Table 1 summarizes the main aspects concerning HVAC control modes addressed in literature.

Besides setting appropriate setback and set point temperatures, also mechanical ventilation can be controlled and adjusted. Ventilation operations can be tailored in accordance with people's presence, number of occupants in the supplied environment, and $\mathrm{CO}_{2}$ concentration (Chenari et al. 2016). The main aspects affected by different ventilation operations are as follows: supply airflow rate, temperature, air change rate, ventilation efficiency, potential energy saving, and generally, healthy space conditions (Cao et al. 2014). Tests on case studies demonstrate that ventilation energy consumption can be decreased by $22 \%$ when the ventilation system is controlled based on the number of occupants, instead of running at fixed flow rate during occupancy scheduled period (Chenari et al. 2017).

The effects of fixed and temperature-controlled ventilation have often been compared, discussing on the 
Table 1 Main references for systems of the control of HVAC systems

\begin{tabular}{|c|c|}
\hline Issue & Ref. \\
\hline $\begin{array}{l}\text { Effects of transition time and pre-heating on } \\
\text { energy saving }\end{array}$ & $\begin{array}{l}\text { (Candanedo et al. 2015; Date et al. 2015; } \\
\text { Gunay et al. 2016; Kleiminger et al. 2014) }\end{array}$ \\
\hline $\begin{array}{l}\text { Influence of modulation set point strategies on } \\
\text { energy saving }\end{array}$ & (Fournier and Leduc 2014) \\
\hline Effect of schedules on energy saving & (Fadzli Haniff et al. 2013; Lee et al. 2013) \\
\hline $\begin{array}{l}\text { Adoption of real occupancy schedules for } \\
\text { estimating energy consumptions }\end{array}$ & (Gupta et al. 2009; Lee et al. 2013; Lu et al. 2010) \\
\hline $\begin{array}{l}\text { Adoption of pre-defined occupancy schedule } \\
\text { for estimating energy consumptions }\end{array}$ & $\begin{array}{l}\text { (Cetin et al. 2016; Fournier and Leduc 2014; } \\
\text { Ghahramani et al. 2016; Gunay et al. 2016; } \\
\text { Moon and Han 2011; Pritoni et al. 2016; } \\
\text { Ruivo et al. 2013) }\end{array}$ \\
\hline $\begin{array}{l}\text { Adoption of control strategies for reducing } \\
\text { peak demand }\end{array}$ & $\begin{array}{l}\text { (Candanedo et al. 2015; Cetin et al. 2016; } \\
\text { Date et al. 2015; Fadzli Haniff et al. 2013; } \\
\text { Fournier and Leduc 2014) }\end{array}$ \\
\hline $\begin{array}{l}\text { Control of comfort conditions coupled with } \\
\text { energy saving }\end{array}$ & (Cetin et al. 2016; Kleiminger et al. 2014) \\
\hline
\end{tabular}

adoption of different technological solutions; however, people's presence is not taken into account (Kontoleon and Bikas 2006).

The authors propose a comprehensive analysis of mixed control modes for heating, ventilation, and opening windows. In fact, up to authors' knowledge, such comprehensive analysis is lacking in literature. Several researches have addressed specific and focused issues (listed in Table 2) and correlated these issues to specific controls (fixed or intelligent, referring to opening windows or HVAC conditions). An assessment that combines specific people behaviors to different control modes has not yet been performed. This paper aims to present such assessment estimating the reduction of home HVAC energy demand in cold and mild European climate conditions when different intelligent ICT-driven technologies (meant for tackling energy hungry behaviors), already available in the market, are adopted. The paper aims to analyze how energy demand can be reduced combining different control modes for heating, ventilation, and opening windows in homes.

Table 2 State-of-the-art approaches for control modes of heating, ventilation, and opening windows

\begin{tabular}{|c|c|c|c|c|}
\hline Issue & Opening windows & $\begin{array}{l}\text { HVAC } \\
\text { control-heating }\end{array}$ & $\begin{array}{l}\text { HVAC } \\
\text { control—ventilation }\end{array}$ & Ref. \\
\hline $\begin{array}{c}\text { Effects of occupants on } \\
\text { energy consumption }\end{array}$ & Fixed control & Fixed control & Fixed control & (Karjalainen 2016) \\
\hline $\begin{array}{l}\text { Relation between occupants' } \\
\text { activities and window control }\end{array}$ & Fixed control & & & (Jeong et al. 2016) \\
\hline $\begin{array}{l}\text { Factors influencing occupant } \\
\text { behavior for opening windows }\end{array}$ & Fixed control & & & (Fabi et al. 2012) \\
\hline $\begin{array}{l}\text { Heating set point modulation } \\
\text { strategies }\end{array}$ & & Fixed and intelligent control & & (Fournier and Leduc 2014) \\
\hline $\begin{array}{l}\text { Length of the temperature } \\
\text { setback-to-set point transition } \\
\text { period and consequent energy } \\
\text { savings }\end{array}$ & & Intelligent control & Intelligent control & (Gunay et al. 2016) \\
\hline $\begin{array}{l}\text { Effect of temperature setbacks in } \\
\text { buildings with intermittent } \\
\text { occupancy }\end{array}$ & & Fixed control & & (Terrill and Rasmussen 2016) \\
\hline $\begin{array}{l}\text { Occupancy-based approaches } \\
\text { for smart heating control }\end{array}$ & & Intelligent control & & (Kleiminger et al. 2014) \\
\hline
\end{tabular}




\section{Methodology}

As mentioned within "Introduction," an enhanced use of existing ICT devices (e.g., sensors combined with specific interacting platforms) can potentially tackle people energy hungry behaviors in buildings (Pasini et al. 2017). Authors did a comprehensive literature review (for more information refer to "Literature review") identifying as potential aspects to consider for enabling consistent energy savings: setting properly HVAC operations and opening of windows. Both aspects, if not properly handled by building occupants, can result into energy hungry behaviors. As illustrated within the introduction section, these could be avoided by using specific ICT-enabled control, meant for promoting energy behavioral changes (Pasini et al. 2017; Reda et al. 2017).

Different scenarios have been simulated, using IDAICE software ("IDA ICE-Simulation Software | EQUA" n.d.), for estimating impacts on building energy demand of specific people's actions (opening of windows, setting ventilation airflow rates, setback and indoor set point temperatures), which could lead to energy hungry behaviors.

As expressed by (Moon and Jung 2016), although building energy simulation models can to some extent be calibrated with data collected via building audits, the remaining parameters, which are difficult to measure or non-measurable parameters (e.g., solar heat gain, heat gain from occupants, heat loss due to opening of windows), are usually assumed with the help of certified weather data set, national standards. These are all manually inserted in the software used. Thus, this procedure has historically yielded results that become "highly dependent on the personal judgment of the analyst doing the calibration" (Reddy 2006). Authors of this paper followed the same procedure described before. Naturally, it is important to use a certified and validated software in order to guarantee that the simulation program itself correctly accounts the physics of the analyzed building case and correctly models the HVAC components in order to have a close correspondence with the real world. This validation procedure is usually done by the software provider. In this paper, the used software has been validate by EQUA Simulation AB ("Building Performance-Simulation Software | EQUA" n.d.), which also holds validation reports publicly available. The other side of validation is meant to show that the building model, including HVAC components, is correctly created by the user of the building simulation program. The reliability of the created model can be shown against real-world measurements, another simulation programs, or expert analyses. The best case would be the first. However, it is not always possible to compare simulation results with measured data in all the cases. There are cases in which, due to the complexity of the analyzed case and/or the nature of the analysis itself, this validation procedure cannot be applied due to the lack of meaningful data. As regards the cases presented in this paper, unexpected events, which are obvious to realize in a residential building, contribute to shape the formation of the building energy demand. These events are often difficult to capture for the nature of the events themselves and/ or for the high cost of specific measurement equipment needed to quantify them. Thus, other research (Candanedo et al. 2015; Cetin et al. 2014; Cetin et al. 2016; Chenari et al. 2017; D'Oca et al. 2014; Fabi et al. 2012, 2013; Ghahramani et al. 2016; Gunay et al. 2016; Karjalainen 2007, 2016; Kontoleon and Bikas 2006; Ruivo et al. 2013; Wang and Greenberg 2015; Wang et al. 2017) on similar topics did not pursue a validation against measured data. They all relied on expert analyses for justifying the credibility of simulation models results, carefully analyzing that alterations in energy consumptions and temperatures, due to assumptions and changes in the HVAC controls, were logically and rationally explained. Authors of this paper also adopted this methodology. Moreover, it is worth to mention that (SoleimaniMohseni et al. n.d.) verified that IDA ICE performed well in comparison to similar BES programs.

Three possible control modes (constant, fixed, intelligent) have been assumed for HVAC operations and opening of windows. Combinations of control modes have also been analyzed, considering for instance a constant control mode for the heating system and an intelligent control model for opening of windows. As previously stated, the intelligent control mode is driven by specific ICT solutions, which can be applied separately to heating and ventilation systems and windows. This hypothesis represents concrete options, since such distinct ICT technologies could be separately purchased on the market. Each scenario has been analyzed in terms of building heating demand (space heating and ventilation), indoor temperature, airflow rates (from ventilation and windows), and electrical fan energy consumption. Different heating delivery systems (electric radiator, 
floor heating, and water radiator) and two localities (Helsinki and Milan, representative of cold and mild European climates) have been considered.

As discussed in the introduction section, tailoring system operation based on people's presence potentially generates significant savings. For carefully considering this aspect, authors have derived considerations about people's presence and their habits in adjusting indoor set point temperature from monitored data of a building located in south of Finland. Different occupancy patterns have been identified and associated to specific events, which can potentially occur during a week (Fig. 3, more information within the Appendix Table 19). Hence, the identified patterns have been merged for obtaining a realistic yearly occupancy schedule, which has been considered in the two assessed locations (Milan and Helsinki).

As regards window opening behaviors, literature information and monitored data have been considered. Particularly, windows have been considered open for a fixed time before occupants leave their homes (in the morning) and after they get in (in the evening), as suggested by (Rune Vinther Andersen 2009). Particularly, window opening time of $30 \mathrm{~min}$ has been assumed based on the average of measured data as regards Helsinki cases. Instead as regard Milan cases, the time has been extended to $60 \mathrm{~min}$, considering the different climate conditions and,
Fig. 3 Example of weekly occupancy schedule monitored in a block of flats
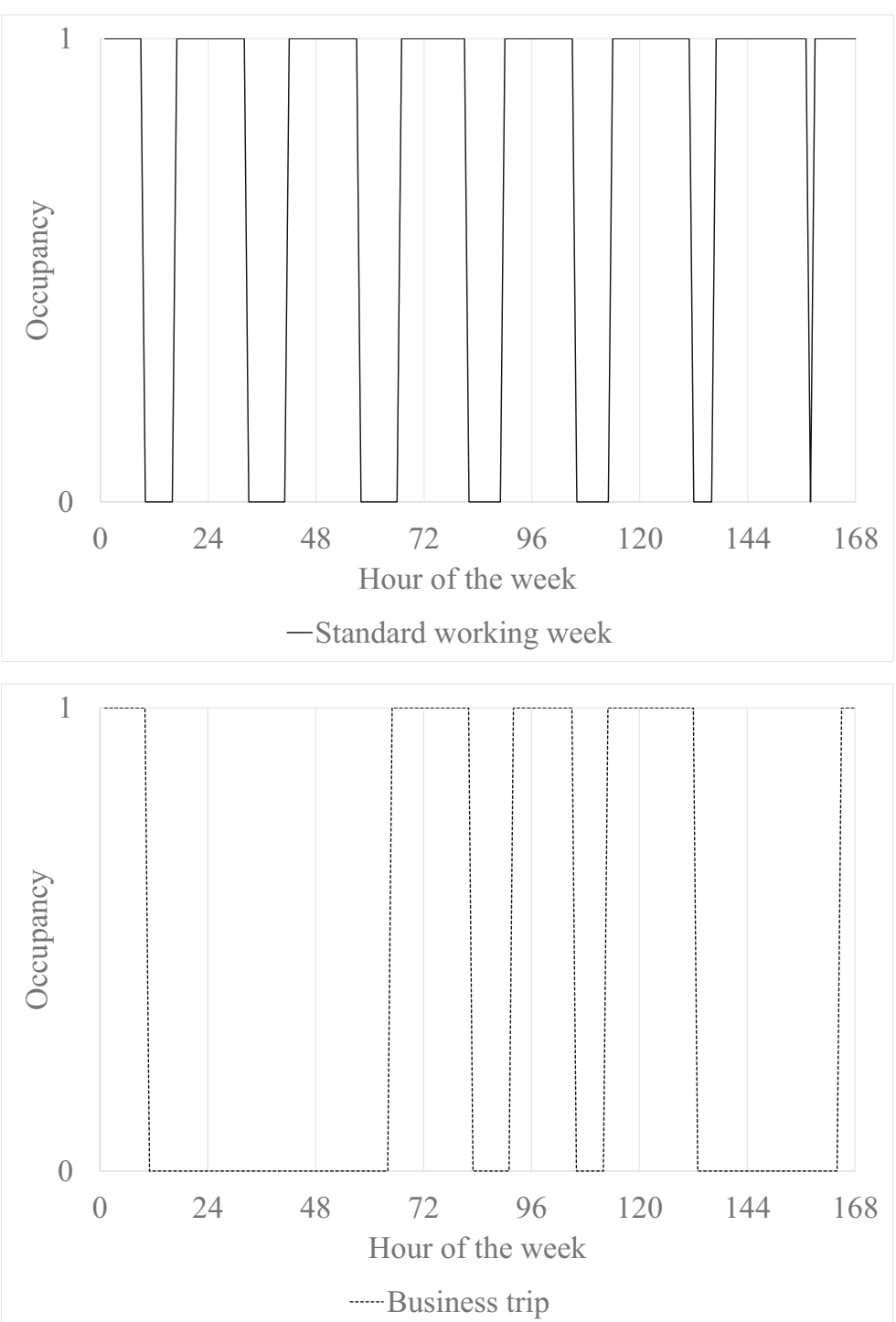
consequently, the different habits of people (as confirmed by authors' direct experience).

Authors have defined different scenarios (a detailed description is reported in Table 9), combining factors as heating delivery systems, people's behaviors in terms of HVAC settings, people's behaviors in terms of opening windows, and intelligent controls for HVAC and opening windows. Simulated cases (a detailed description is reported in Table 10) have been built by combining different scenarios; particularly, 165 cases have been simulated for Helsinki and 45 cases have been simulated for Milan (detailed results are presented in "Results and discussion"). The unbalance between simulated cases for Helsinki and Milan is due to the absence of mechanical ventilation in Milan cases, which reduces the number of combinations.

Before discussing the annual results of different simulated cases, the paper presents specific considerations on a reduced number of cases for improving the readability of the paper.

Particularly, specific scenarios have been selected for presenting how simulation model emulates window airflows, heating distribution systems and mechanical ventilation operations. Moreover, these cases have been also chosen for showing implications on both indoor thermal conditions and ventilation and heating system operations. Authors have reported the daily evolution of indoor temperature, radiator heating power, ventilation electrical power, airflow from windows, and ventilation system as regards two cases. As regards the first case, people do not open the windows, while in the second case, windows are opened according to people's presence. Both cases consider the use of water radiator with mass and an intelligent control mode of HVAC operation (set point to setback transition time and airflow rate based on people's presence).
After these specific considerations, the paper presents and discusses simulation results of all the cases. Results show firstly how people window opening behavior affects the energy building demand when different HVAC control modes (constant, fixed, and intelligent) are adopted and, secondly, how intelligent ICT-driven solutions based on detecting people's presence, $\mathrm{CO}_{2}$ concentration and open windows can support people assuming energy rational behaviors.

\section{Case study}

\section{Building model description}

For performing simulations, an apartment building has been selected as a case study. The building has been simulated as three zones system. Each zone represents one apartment (Fig. 4). The simulated façade of the building is facing south without any solar shading. The volume of each apartment is $180 \mathrm{~m}^{3}$, and the floor area is $70 \mathrm{~m}^{2}$. Hence, the volume of the simulated building is $540 \mathrm{~m}^{3}$ and the floor area is $210 \mathrm{~m}^{2}$.

The geometrical description of the model is the same for Helsinki and Milan, while the adopted envelope technical solutions (Table 3) are different. They have been defined according to national and regional standard references, different for Helsinki (Asuntoministeri et al. 2010) and Milan (Regione Lombardia 2015).

In principle, internal gains consist of people, lighting, and appliances. These have been implemented within the model in accordance with the current Finnish and Italian standards. As regard Helsinki, these loads follow the occupancy presence except a base appliance load of $50 \mathrm{~W}$, which is always on regardless of the occupancy. The maximum loads are presented in Table 4. As

Fig. 4 Simulated building model

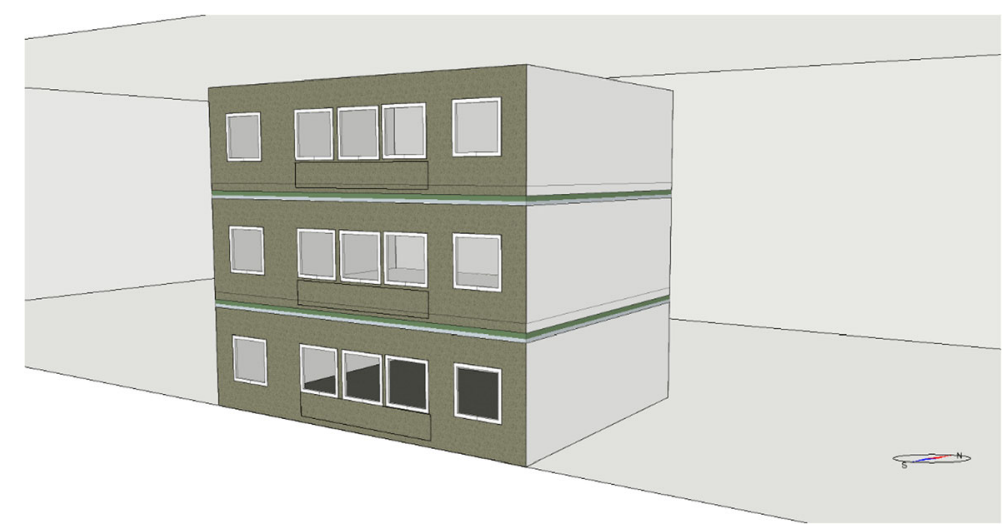


Table 3 Thermal properties and surface areas of the building structures

\begin{tabular}{llll}
\hline Building structure & \multicolumn{2}{l}{$U$ values $\left(\mathrm{W} / \mathrm{m}^{2}, \mathrm{~K}\right)$} & $\begin{array}{l}\text { Surface area }\left(\mathrm{m}^{2}\right) \\
\text { One apartment/total }\end{array}$ \\
\cline { 2 - 3 } & Helsinki & Milan & \\
\hline Outside wall & 0.17 & 0.26 & $17 / 52$ \\
Roof $^{1}$ & - & - & $-/-$ \\
Ground floor & 0.18 & 0.26 & $70 / 70$ \\
Windows & 1.0 & 1.4 & $7.5 / 22.5$ \\
Internal floors & 2.3 & 1.5 & $70 / 210$ \\
Internal walls & 2.1 & 1.6 & $62 / 187$ \\
\hline
\end{tabular}

${ }^{1}$ The simulated part of the building does not have roof

regards Milan cases (Table 5), values have been defined according to national standards (Ente Italiano di Normazione 2014).

Heating and ventilation systems

Helsinki cases comprise mechanical ventilation (supply and exhaust air systems) (Fig. 5). Instead, Milan cases do not consider mechanical ventilation, but natural ventilation.

Design heating powers of Helsinki and Milan cases have been estimated without taking into account internal and solar gains. The heating systems have been dimensioned with a safety factor (over sizing) of $10 \%$. Design heating powers, for both locations, are presented in Table 6. Design supply and return temperatures of heating delivery systems are based on the Finnish design guides for new district heating systems (Finnish Energy 2014); they are presented in Table 7.

As regard design specifications of the ventilation system, including specific fan power (SFP), infiltration airflow rates are listed in Table 8 .

Table 4 Internal loads and their schedules

\begin{tabular}{|c|c|c|}
\hline Heat gain & Maximum load (W) & Schedule \\
\hline Occupancy & 3 people & Occupancy schedule \\
\hline Lighting & 552 & Occupancy schedule \\
\hline Appliance & 270 & $\begin{array}{l}\text { Follows occupancy schedule, } \\
\text { depends linearly on the } \\
\text { number of people at home }\end{array}$ \\
\hline Base load & 50 & Always on \\
\hline
\end{tabular}

Table 5 Internal gains by people and equipment as regards Milan cases

\begin{tabular}{lll} 
Day & $\begin{array}{l}\text { Kitchen and dining room } \\
\left(\Phi_{\text {int,OC }}+\Phi_{\text {int, } \mathrm{A}}\right) / \mathrm{A}_{\mathrm{f}} \\
\left(\mathrm{W} / \mathrm{m}^{2}\right)\end{array}$ & $\begin{array}{l}\text { Other HVAC-equipped } \\
\text { rooms }\left(\Phi_{\text {int,OC }}+\Phi_{\text {int, } \mathrm{A}}\right) / \mathrm{A}_{\mathrm{f}} \\
\left(\mathrm{W} / \mathrm{m}^{2}\right)\end{array}$ \\
\hline Mon-Fri 9 & $\begin{array}{l}2.67 \\
\text { Sat-Sun } 9\end{array}$ & 3.83 \\
\hline
\end{tabular}

\section{Simulated cases}

The variables considered in simulations allow evaluating the effects of:

- Different typologies of heating delivery systems, referring to:

- Electric radiator

- Floor heating

- Water radiator

- Different people behaviors in terms of HVAC settings, considering:

- Constant control modes for set point temperature and ventilation airflow rate

- Fixed set point to setback periods and ventilation schedule

- Intelligent HVAC control mode based on people's presence (tailoring only set point to setback indoor temperature transition time for Milan cases and tailoring both set point to setback indoor temperature transition time and variable ventilation airflow volumes for Helsinki cases

- Intelligent HVAC control mode, tailoring set point to setback transition time and on $\mathrm{CO}_{2}$ concentration level ventilation airflow volumes based on people's presence for Helsinki cases

- Different people behaviors in terms of opening windows, outlining the effects when:

- Windows are sealed or always closed.

- Windows are opened according to a fixed schedule of people's occupancy.

- Windows are opened in accordance with $\mathrm{CO}_{2}$ concentration level. 


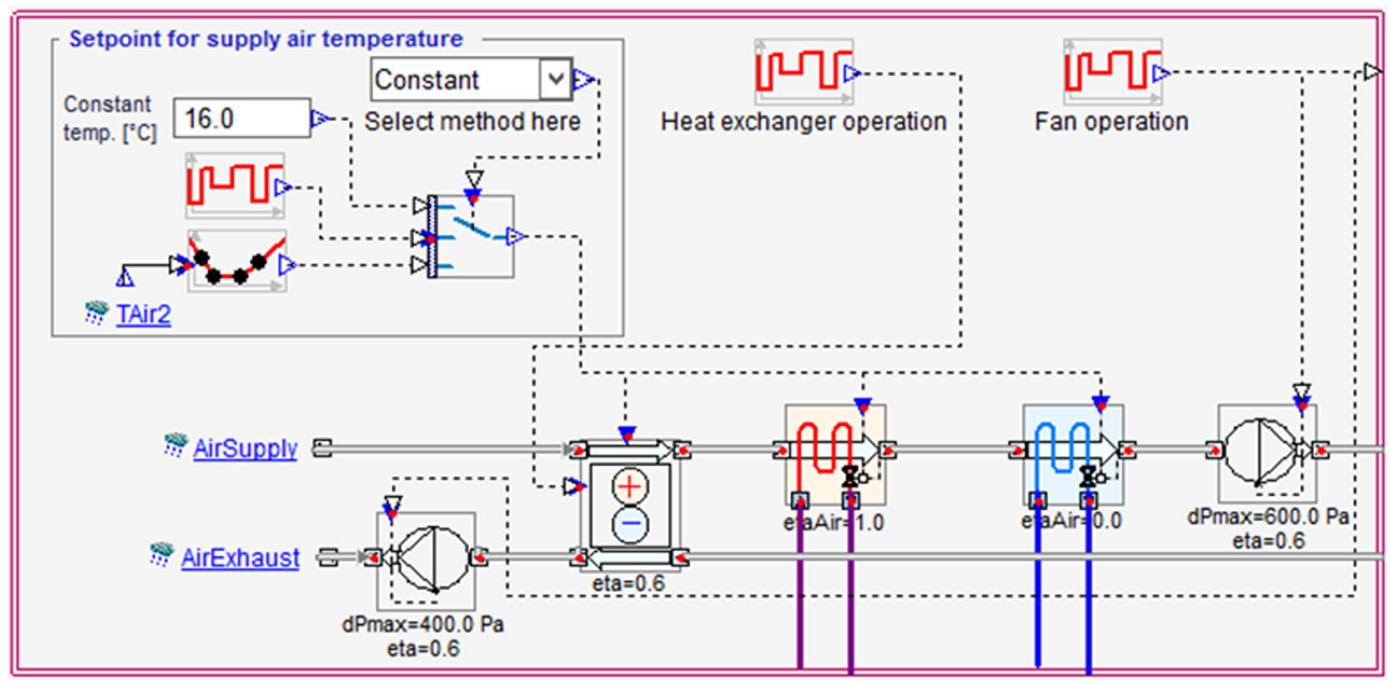

Fig. 5 Typical mechanical ventilation system used in Finland

Specifically, $\mathrm{CO}_{2}$ concentration level has been kept below $1000 \mathrm{ppm}$, which refers to satisfactory conditions in accordance with Finnish standards (AA.VV. 2010; Johansson et al. 2015).

All scenarios are presented in Table 9. A number has been associated to each of them in order to simplify the discussion of results.

The presented scenarios have been combined for simulating different cases, presented in Table 10. The simulated cases are summarized in Table 10, referring to a generic heating delivery system while outlining the effects of different people behaviors related to opening of windows and setting HVAC operations (for heating and ventilation).

Simulated cases in Table 10 are described using numbering introduced in Table 9 with the exception of

Table 6 Design space heating powers of zones

\begin{tabular}{lll}
\hline Apartment & \multicolumn{2}{l}{$\begin{array}{l}\text { Design heating power with 10\% over } \\
\text { dimensioning (W) }\end{array}$} \\
\cline { 2 - 3 } & $\begin{array}{l}\text { Helsinki } \\
\text { Dimensioning } \\
\text { outdoor air } \\
\text { temperature }-26{ }^{\circ} \mathrm{C}\end{array}$ & $\begin{array}{l}\text { Milan } \\
\text { Dimensioning } \\
\text { outdoor air } \\
\text { temperature }-10{ }^{\circ} \mathrm{C}\end{array}$ \\
\hline Ground floor & 1420 & 1520 \\
Middle floor & 970 & 1250 \\
Top floor & 980 & 1230 \\
Air handling unit & 2650 & - \\
\hline
\end{tabular}

the heating delivery system, mentioned with " $x$ " as it refers to a not specified heating delivery system.

As an example, the case $\mathrm{x} 31$ represents the scenario with a not-specified heating delivery system, where set point to setback transition time and ventilation airflow rate are ICT-supported, being tailored on people's presence $(y=3)$, and window opening behavior is managed according to people's presence $(z=1)$.

The simulated cases are summarized in Fig. 6 .

\section{Results and discussion}

As introduced in "Methodology," the paper aims to outline the impact of specific occupant behaviors on building energy demand assessing also the benefits of using intelligent ICT-driven solutions for supporting people assuming energy rational behaviors.

Before discussing the annual results of simulated cases, the paper presents detailed considerations on a reduced number of cases. In fact, due to the huge number of simulated cases and in order to improve the readability of the paper, the paragraph "HVAC operations and indoor thermal conditions" reports findings only related to water radiator $(x=3$; Table 9).

Firstly, daily evolution of indoor temperature, radiator heating power, ventilation electrical power, airflow from windows, and ventilation system are introduced for three cases (cases 33, 331, and 3311; for a detailed description, refer to Table 9, considering $x=3$ and $y=3$ for all the cases, $z=1$ for the second and the third cases and $t=1$ for 
Table 7 Design space heating delivery systems temperatures for considered distribution system

\begin{tabular}{|c|c|c|}
\hline \multirow[t]{2}{*}{$\begin{array}{l}\text { Heating delivery } \\
\text { system }\end{array}$} & \multicolumn{2}{|c|}{$\begin{array}{l}\text { Design weather compensation temperatures } \\
\text { supply/return/room/outdoor }\left({ }^{\circ} \mathrm{C}\right)\end{array}$} \\
\hline & Helsinki & Milan \\
\hline Electric heaters & - & - \\
\hline Water radiators & $45 / 30 / 22 /-26$ & $45 / 30 / 22 /-10$ \\
\hline Floor heating & $35 / 30 / 22 /-26$ & $35 / 30 / 22 /-10$ \\
\hline
\end{tabular}

the third case). The first case does not consider window opening behavior, while the second and the third do. The choice of focusing on these cases lies on two reasons: presenting how simulation model emulates main considered aspects (window airflows, heating distribution system and mechanical ventilation operations) and supporting the reader understanding the implications of scenarios on both indoor thermal conditions and operations of ventilation and heating system. Finally, impacts on specific people behaviors on building energy demand are discussed. The considered behaviors concern setting indoor air set point temperature, setting ventilation airflow rates, and opening windows. Moreover, benefits of particular HVAC operations adopting an intelligent control mode are presented in terms of heating energy demand reductions. Actually, considerations about particular ICT solutions, which could be useful to turn energy hungry behaviors into energy rational behaviors, are also elaborated while presenting impacts of specific people behaviors on building energy demand.

HVAC operations and indoor thermal conditions

In-depth considerations, referring to three cases (cases 33,331 , and 3311), are presented, considering evolution of indoor temperature, radiator heating power, ventilation electrical power, airflow from windows, and ventilation system along one winter day.

Figure 7 shows indoor temperature, outdoor temperature, airflow rates from windows, and ventilation system for the cases 33 and 3311 (described in Table 9). When the window is opened (case 3311, after users arrive at home and before they leave, approximately around hours 12 and 22, Fig. 7), due to a cold air stream coming inside (window airflow; Fig. 7-right), indoor temperature drastically reduces. Once the window is closed (no window airflow), indoor air temperature moderately increases, reaching $21{ }^{\circ} \mathrm{C}$ (Fig. 7-right) due to building thermal mass. Then, indoor temperature slowly decreases until window is opened again (for more information about window opening behaviors refer to "Methodology"). If opening windows is not considered (case 33), indoor temperature decreases as soon as people leave the apartment for increasing again when people come back home in the evening, respectively around approximately hours 12.5 and 21.5 (Fig. 7left). Specifically, this is the effect of indoor temperature setback (considering that $y=3$ in the discussed cases means that set point to setback transition time and ventilation airflow volumes are tailored on people's presence, as specified in Table 9).

When air temperature setback is in place, the heating system is turned off, until the indoor air temperature reaches the temperature setback, and mechanical ventilation system delivers the minimum airflow rate (for more information about HVAC operation refer to "Heating and ventilation systems"). This is noted in Fig. 8, which depicts heating power of radiators and heating power and fan consumption for ventilation and indoor temperature for the cases 331 and 3311. Orange area of Fig. 8 represents HVAC heating energy demand; blue area represents heating energy demand for ventilation; green area represents fan consumption for ventilation.
Table 8 Ventilation and infiltration plus SFP of the ventilation unit

\begin{tabular}{|c|c|c|}
\hline \multirow[t]{2}{*}{ Ventilation system } & \multicolumn{2}{|l|}{ Airflows and other information } \\
\hline & Helsinki & Milan \\
\hline $\begin{array}{l}\text { Mechanical supply and } \\
\text { exhaust air system }\end{array}$ & $\begin{array}{l}\text { Max airflow } 0,5 \mathrm{dm}^{3} / \mathrm{s}, \mathrm{m}^{2} \\
\text { Min airflow } 0,15 \mathrm{dm}^{3} / \mathrm{s}, \mathrm{m}^{2} \\
\text { Heat recovery rate } 45 \% \\
\mathrm{SFP}=2,0 \mathrm{~kW} /\left(\mathrm{m}^{3} / \mathrm{s}\right)\end{array}$ & - \\
\hline Natural ventilation & - & Included in infiltration \\
\hline Infiltration & $\begin{array}{l}0,13 \mathrm{~m}^{3} /\left(\mathrm{h}, \text { envelope- } \mathrm{m}^{2}\right) \\
\quad\left(\text { air tightness } 2 \mathrm{~m}^{3} /\left(\mathrm{h}, \text { envelope- } \mathrm{m}^{2}\right)\right)\end{array}$ & $\begin{array}{l}10,80 \mathrm{~m}^{3} /\left(\mathrm{h} \text {, envelope- } \mathrm{m}^{2}\right) \\
\quad(\text { air change rate } 0.451 / \mathrm{h})\end{array}$ \\
\hline
\end{tabular}


Table 9 Scenarios considered in simulations

\begin{tabular}{|c|c|c|c|c|c|}
\hline \multicolumn{2}{|c|}{ Scenario } & Description & \multirow{4}{*}{$\begin{array}{l}\text { Constant } \\
\text { control }\end{array}$} & \multirow{2}{*}{$\begin{array}{l}\text { Fixed } \\
\text { control }\end{array}$} & \multirow{2}{*}{$\begin{array}{l}\text { Intelligent } \\
\text { control }\end{array}$} \\
\hline$x$ & Heating delivery system & 1 Electric radiator & & & \\
\hline & & 2 Floor heating & & & \\
\hline & & 3 Water radiator & & & \\
\hline \multirow{4}{*}{\multicolumn{2}{|c|}{$y$ HVAC setting behavior }} & $\begin{array}{l}1 \text { Constant HVAC control mode - indoor temperature set point and ven- } \\
\text { tilation airflow rate are fixed to design conditions }\end{array}$ & $\mathrm{X}$ & & \\
\hline & & $\begin{array}{l}2 \text { Fixed HVAC control mode-indoor temperature set point and ventila- } \\
\text { tion airflow rate have fixed setback times }\end{array}$ & & $\mathrm{X}$ & \\
\hline & & $\begin{array}{c}3 \text { Intelligent HVAC control mode } 1-\text { set point to setback transition time } \\
\text { and ventilation airflow volumes are tailored on people's presence }\end{array}$ & & & $\mathrm{X}$ \\
\hline & & $\begin{array}{l}4 \text { Intelligent HVAC control mode } 2 \text { - set point to setback transition time is } \\
\text { tailored on people's presence and ventilation airflow volumes are } \mathrm{CO}_{2} \\
\text { controlled }\end{array}$ & & & $\mathrm{X}$ \\
\hline \multirow[t]{2}{*}{$z$} & $\begin{array}{l}\text { Window opening } \\
\text { behavior }\end{array}$ & $\begin{array}{l}1 \text { Window opened after arriving (in the evening) and before leaving the } \\
\text { house (in the morning) for a fixed period }\end{array}$ & & $\mathrm{X}$ & \\
\hline & & $\begin{array}{l}2 \text { Window intelligent control mode- opening windows based on } \mathrm{CO}_{2} \\
\text { concentration }\end{array}$ & & & $\mathrm{X}$ \\
\hline$t$ & $\begin{array}{l}\text { Control on HVAC system } \\
\text { when windows opened }\end{array}$ & $\begin{array}{l}1 \text { Window and intelligent HVAC control mode-when the window is } \\
\text { opened, the heating system is turned off }\end{array}$ & & & $X$ \\
\hline
\end{tabular}

Moreover, Fig. 8 visually identifies intelligent HVAC control operations of both heating delivery and mechanical ventilation systems: both are turned off when the window is open (approximately around hours 12 and 22; Fig. 8 -right).

Interesting to notice is that, if the HVAC is not controlled when windows are opened (case 331), two power peaks occur when the window is open. The first is about $1050 \mathrm{~W}$, while the second is $1600 \mathrm{~W}$ (case 331; Fig. 8-left). Instead, when HVAC is controlled (case 3311 ), only one peak of $1600 \mathrm{~W}$ occurs when occupants close the window in the evening (case 3311; Fig. 8right). Besides generating a slightly higher heating demand peak in the evening, controlling the HVAC system, when windows are opened, also lightly affects indoor air temperature; temperatures drops to $17.8^{\circ} \mathrm{C}$ (Fig. 8 -right) instead of $18.1{ }^{\circ} \mathrm{C}$ (Fig. 8-left).

The ventilation setback affects the electrical energy consumption of supply and exhaust air fans in Helsinki cases (mechanical ventilation is not present in Milan cases). Table 11 summarizes the electricity consumption of the fans and the relative saving potential compared to constant operations of the fans (constant air volume system, no setback).

HVAC demand during the considered winter day is $13.6 \mathrm{kWh}$ for case 331 and $12.8 \mathrm{kWh}$ for case 3311 . This indicates that relatively small savings can be achieved adopting an intelligent HVAC control for shutting down the heating system when windows are opened.

Summarizing, both Figs. 7 and 8 show the effect of the most complete intelligent HVAC control mode among the considered control possibilities. Indeed, looking at both Figs. 7 and 8, functionalities of such advanced control can be appreciated:

- When windows are opened, Fig. 7-right shows that ventilation is shut down and Fig. 8 shows that both heating and ventilation are shut down.

- The intelligent control ensures reaching the set point temperatures $\left(22^{\circ} \mathrm{C}\right)$ only when people are at home (Fig. 8).

- When nobody is at home, due to indoor temperature and ventilation setbacks implementation, indoor temperature is below $22{ }^{\circ} \mathrm{C}$ (Fig. 7) and only mechanical ventilation is triggered (heating system is turned off; Fig. 8).

Impact of specific behaviors on building energy demand

The impact on heating energy demand of people behaviors is presented in relation to:

- Setting HVAC operations (constant and fixed control modes; for more information refer to Table 10) 
Table 10 Different simulation cases with reference to a generic heating delivery system (referred to with a generic $\mathrm{x}$ instead of the specific number, as described in Table 9)

\begin{tabular}{|c|c|}
\hline Number & Cases \\
\hline $\mathrm{x} 1$ & Constant HVAC control mode \\
\hline x11 & $\begin{array}{l}\text { Constant HVAC control mode + people window opening } \\
\text { behavior }\end{array}$ \\
\hline $\mathrm{x} 111$ & $\begin{array}{l}\text { Constant HVAC control mode }+ \text { people window opening } \\
\text { behavior }+ \text { intelligent heating system control when windows } \\
\text { are opened }\end{array}$ \\
\hline $\mathrm{x} 12$ & $\begin{array}{l}\text { Constant HVAC control mode }+ \text { intelligent control on opening } \\
\text { windows based on } \mathrm{CO}_{2} \text { level }\end{array}$ \\
\hline $\mathrm{x} 121$ & $\begin{array}{l}\text { Constant HVAC control mode }+ \text { intelligent control on opening } \\
\text { windows based on } \mathrm{CO}_{2} \text { level }+ \text { intelligent heating system } \\
\text { control when windows are opened }\end{array}$ \\
\hline $\mathrm{x} 2$ & Fixed HVAC control mode \\
\hline
\end{tabular}

Description

Indoor temperature set point and ventilation airflow rate are fixed to design conditions.

Same as case $\mathrm{x} 1+$ with one window opened after arriving (in the evening) and before leaving the house (in the morning) for $30 \mathrm{~min}$ as regards Helsinki and $60 \mathrm{~min}$ as regard Milan.

Same as case $\mathrm{x} 11+$ when the window is opened the heating system is turned off.

Same as case $\mathrm{x} 1+$ with one window opened based on the $\mathrm{CO}_{2}$ level. The window is opened linearly from 0 to 0.5 ( $1=$ fully open) when $\mathrm{CO}_{2}$ level rises from 1000 to $1200 \mathrm{ppm}$.

Same as case $\mathrm{x} 12+$ when the window is opened the heating system is turned off.

Indoor temperature set point and ventilation airflow rate have fixed setback times between 8:00 and 17:00 o'clock. During this period, set point temperature is decreased by $7{ }^{\circ} \mathrm{C}$ and ventilation is turned to minimum flow rate (see Table 8).

x21 Fixed HVAC control mode + people window opening behavior Same as case $\mathrm{x} 2+$ window opened after arriving (in the evening) and before leaving the house (in the morning) for $30 \mathrm{~min}$ as regards Helsinki and $60 \mathrm{~min}$ as regard Milan.

x211 Fixed HVAC control mode + people window opening behavior + intelligent heating system control when windows are opened

x22 Fixed HVAC control mode + intelligent control on opening windows based on $\mathrm{CO}_{2}$ level

x221 Fixed HVAC control mode + intelligent control on opening windows based on $\mathrm{CO}_{2}$ level + intelligent heating system control when windows are opened

x3 Intelligent HVAC control mode 1 Same as case $\mathrm{x} 21+$ when the window is opened the heating system is turned off.

Same as case $\mathrm{x} 2+$ window opened based on the $\mathrm{CO}_{2}$ level. The window is opened linearly from 0 to 0.5 ( 1 = fully open $)$ when $\mathrm{CO}_{2}$ level rises from 1000 to $1200 \mathrm{ppm}$.

Same as case $\mathrm{x} 22+$ when the window is opened the heating system is turned off.

Set point to setback transition time and ventilation airflow volumes is tailored on people's presence. The heating set point temperature is decreased by $7{ }^{\circ} \mathrm{C}$ and ventilation is turned to minimum flow rate (see Table 8) when there are no people in the house.

x31 Intelligent HVAC control mode $1+$ people window opening behavior

x311 Intelligent HVAC control mode $1+$ people window opening behavior + intelligent heating system control when windows are opened

x32 Intelligent HVAC control mode $1+$ intelligent control on opening windows based on $\mathrm{CO}_{2}$ level

x321 Intelligent HVAC control mode $1+$ intelligent control on opening windows based on $\mathrm{CO}_{2}$ level + intelligent heating system control when windows are opened

Same as case $\mathrm{x} 3+$ window opened after arriving (in the evening) and before leaving the house (in the morning) for $30 \mathrm{~min}$ as regards Helsinki and $60 \mathrm{~min}$ as regard Milan.

Same as case $\mathrm{x} 31+$ when the window is opened the heating system is turned off.

Same as case $\mathrm{x} 3+$ window opened based on the $\mathrm{CO}_{2}$ level. The window is opened linearly from 0 to 0.5 ( 1 = fully open $)$ when $\mathrm{CO}_{2}$ level rises from 1000 to $1200 \mathrm{ppm}$.

Same as case $\mathrm{x} 32+$ when the window is opened the heating system is turned off.

Set point to setback transition time is tailored on people's presence and ventilation airflow volumes are $\mathrm{CO}_{2}$-controlled. The heating set point temperature is decreased by $7{ }^{\circ} \mathrm{C}$ and ventilation is turned to minimum flow rate (see Table 8) when there are no people in the house. 
Table 10 (continued)

\begin{tabular}{|c|c|c|}
\hline Number & Cases & Description \\
\hline $\mathrm{x} 41$ & $\begin{array}{l}\text { Intelligent HVAC control mode } 2+\text { people window opening } \\
\text { behavior }\end{array}$ & $\begin{array}{l}\text { Same as case } \mathrm{x} 4+\text { window opened after arriving (in the } \\
\text { evening) and before leaving the house (in the morning) for } \\
30 \text { min as regards Helsinki and } 60 \text { min as regard Milan. }\end{array}$ \\
\hline $\mathrm{x} 411$ & $\begin{array}{l}\text { Intelligent HVAC control mode } 2+\text { people window opening } \\
\text { behavior }+ \text { intelligent heating system control when windows } \\
\text { are opened }\end{array}$ & $\begin{array}{l}\text { Same as case } x 41+\text { when the window is opened the heating } \\
\text { system is turned off. }\end{array}$ \\
\hline
\end{tabular}

- Opening of windows when different HVAC control modes are adopted (constant, fixed and intelligent control modes; for more information refer to Table 10).

\section{Moreover, support of:}

- Intelligent solutions based on people's presence (setting of set point to setback transition time and/or of ventilation airflow volumes; for more information, refer to Table 10)

- Intelligent solutions based on $\mathrm{CO}_{2}$ concentration (setting of ventilation and/or control of opening windows; for more information refer to Table 10)

- Intelligent HVAC-window controls (turning off the heating system when windows are opened; for more information refer to Table 10)

are discussed in parallel per each relevant case.

In order to make the comparison of multiple cases more intuitive, each result is presented as a variation of the heating demand, evaluated as follows:

$\Delta(\mathrm{z}, \mathrm{y})=(\mathrm{z}-\mathrm{y}) / \mathrm{y} \times 100$

where $z$ and $y$ are the heating demands of the considered cases. Results are reported as percentage, distinguishing between AHU (air handling unit, mechanical ventilation) and space heating share of the total heating energy demand variation for Helsinki cases and as total heating energy demand variation for Milan cases (mechanical ventilation is not considered).

As an example, referring to Tables 12, 13, 14, 15, 16, 17 , and 18 , the result $\Delta \mathrm{x} 11 / \mathrm{x} 1$ means that, for each heating delivery system, the variation of the heating demand of the case $\mathrm{x} 11$ has been compared to the variation of the heating demand of the case $\mathrm{x} 1$. In other words, energy demand reached with constant HVAC control mode when people open windows at fixed times (case $\mathrm{x} 11$ ) has been compared to energy demand reached with constant HVAC control mode when windows are always closed (case $\mathrm{x} 1$ ).

In order to evaluate the impact of people's behaviors, related to setting HVAC operations, on heating energy demand, a comparison has been performed between cases when people never adjust HVAC settings and when people adopts pre-set schedules. Hence, constant $(y=1$; Table 9) and fixed ( $y=2$; Table 9) controls have been compared. Constant control has been assumed as base case (for details refer to $\mathrm{x} 1$ in Table 12). As regards Helsinki, a $29 \%$ reduction of heating demand can be reached by setting schedules for HVAC operations (for details refer to $\Delta(\mathrm{x} 2, \mathrm{x} 1)$ in Table 12) instead of setting constant working conditions for HVAC (case $\mathrm{x} 1$, described in Table 10). Therefore, the adoption of a fixed HVAC control mode ensures a reduction of the heating demand compared to a constant control mode.

As regard Milan, a minor reduction of heating demand is achieved compared to Helsinki cases (Table 12). Indeed, only a $2 \%$ reduction is registered (for details refer to $\Delta(\mathrm{x} 2, \mathrm{x} 1)$ in Table 12). This is due to the considerably lower building heating demand of Milan cases compared to Helsinki cases.

Impact on heating energy demand of window opening behaviors has been evaluated for both constant and fixed HVAC control modes. When people open windows, they greatly affect the heating demand, as shown in Table 13. Simulations with different heating delivery systems and different HVAC control modes report that opening windows drastically increases the heating demand in all the cases. Results report an average increase of $35 \%$ in Helsinki and $84 \%$ in Milan when a constant HVAC control mode is adopted (for details refer to $\Delta(\mathrm{x} 11, \mathrm{x} 1)$ in Table 13$)$. Instead, a $45 \%$ increment for Helsinki and a $75 \%$ increment for Milan is registered when a fixed control is adopted (for details refer to $\Delta(\mathrm{x} 21, \mathrm{x} 2)$ in Table 13$)$. As regards Helsinki cases, for 


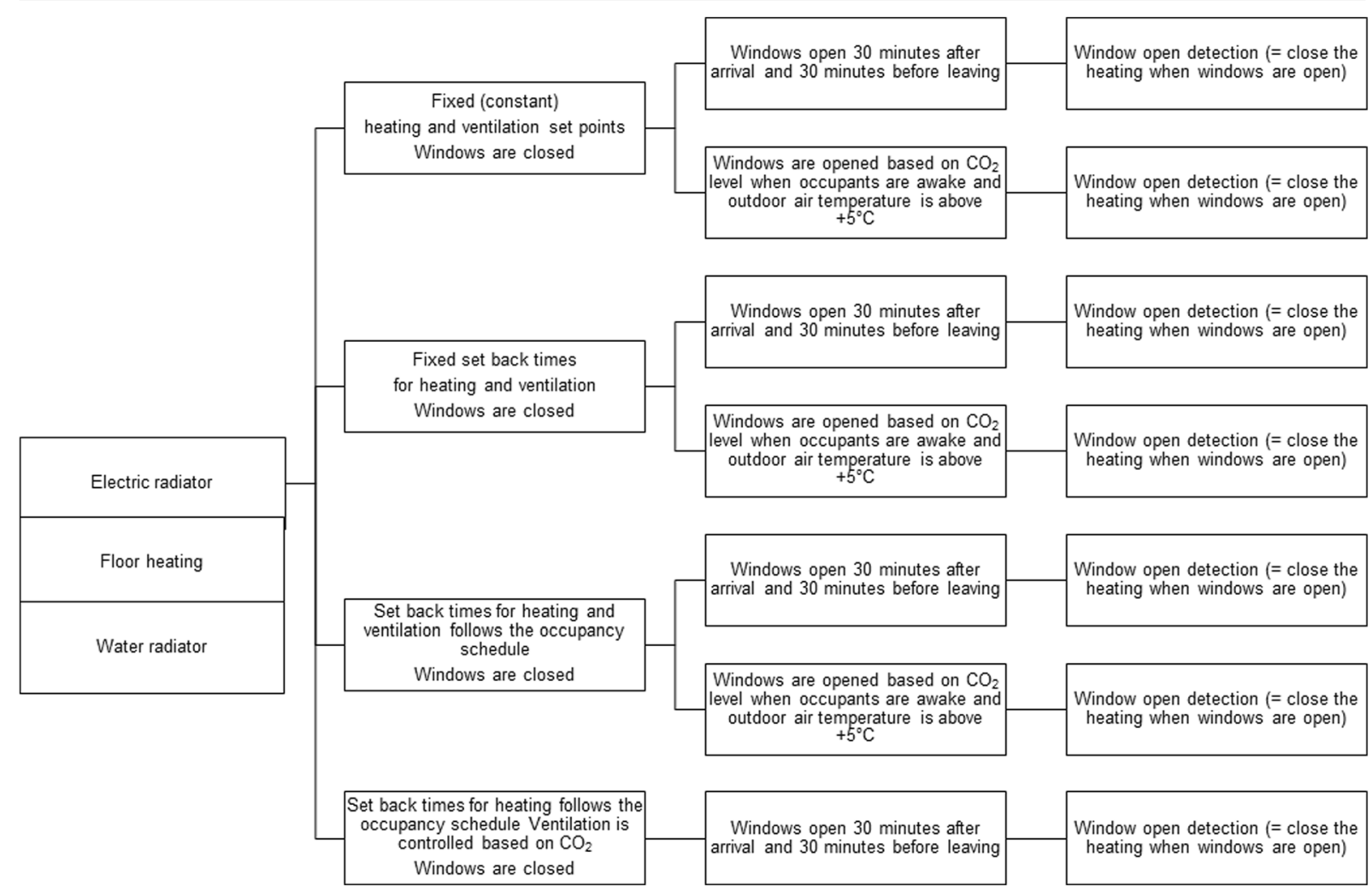

Fig. 6 Simulated cases

both constant and fixed HVAC control modes, the increase of heating demand has to be mainly attributed to an increment of the space heating demand (and not to AHU demand).

Intelligent ICT-driven solutions can be applied to the cases presented before for supporting people reducing the heating demand. Particularly, the heating demand can be reduced by adopting intelligent solutions based on people's presence. Among them, the use of an intelligent HVAC control mode able to tailor both set point to setback indoor temperature transition time and airflow rates according to real people's presence (referred as to intelligent HVAC control 1; Table 10) has been firstly considered. Set point temperature is automatically decreased to the setback temperature and ventilation is turned to the minimum flow rate when people are not
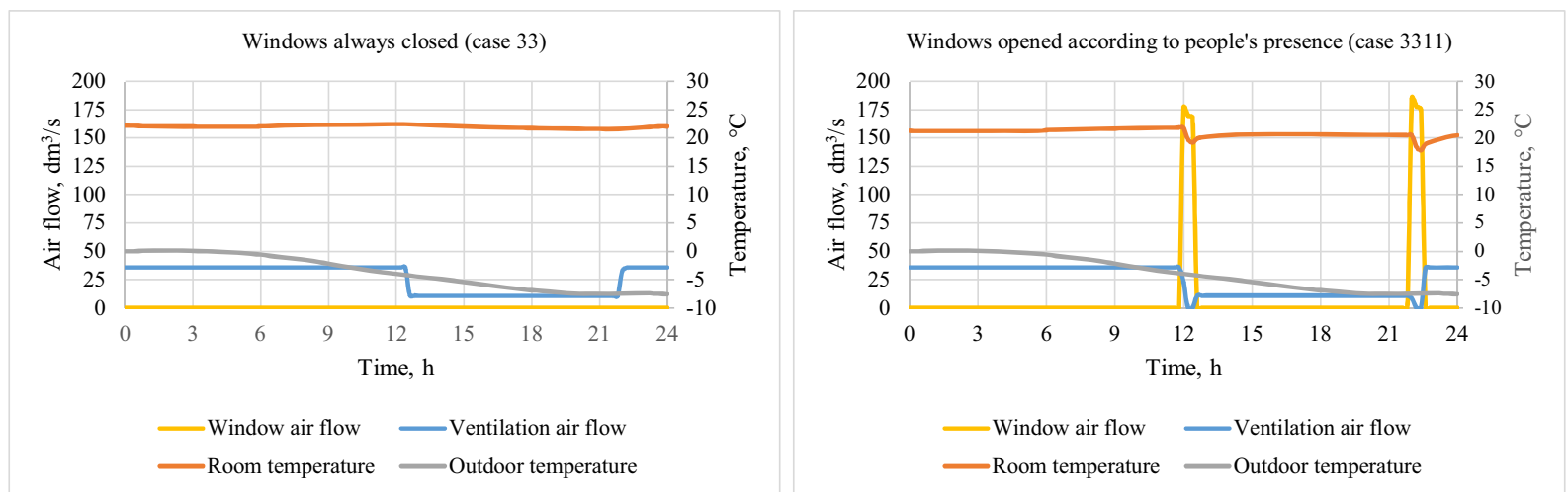

Fig. 7 Indoor temperature and airflow in case of water radiator and intelligent HVAC control (heating and ventilation setback according to people's presence), without (case 33-left) and with (case 3311 — right) window opening behaviors. Presented day is January 20 


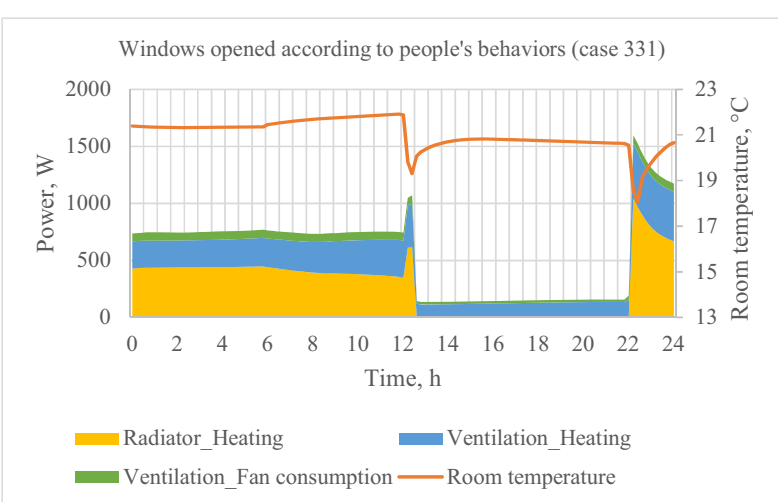

Fig. 8 Indoor temperature, radiator power, ventilation power, and fan consumption in case of water radiator and intelligent HVAC control based on heating and ventilation setback according to people's presence (case 331-left) or HVAC control based on

at home. Such intelligent control is able to save $27 \%$ of building heating demand for Helsinki cases and $6 \%$ for Milan cases compared to constant HVAC control case (for details refer to $\Delta(\mathrm{x} 3, \mathrm{x} 1)$ in Table 12$)$.

As regard Helsinki context, cases $\mathrm{x} 2$ (as described in Table 10) ensure a major reduction than cases $\mathrm{x} 3$ (as described in Table 10). This means that adopting fixed HVAC control mode ensures a major reduction of heating demand than adopting intelligent HVAC control mode based on people's presence (for a comparison refer to $\Delta(\mathrm{x} 2, \mathrm{x} 1)$ and $\Delta(\mathrm{x} 3, \mathrm{x} 1)$ in Table 12$)$. This is due to the fact that the HVAC system works more in case $\mathrm{x} 3$. The intelligent HVAC control based on people's presence makes the HVAC system working when people are at home. On the contrary, with a HVAC fixed control, there are some periods when people are at home and the HVAC system is turned off and some periods when people are not at home and the HVAC works.

On the contrary, cases $\mathrm{x} 3$ ensure a major reduction than cases $\mathrm{x} 2$ in Milan (for a comparison refer to $\Delta(\mathrm{x} 2, \mathrm{x} 1)$ and $\Delta(\mathrm{x} 3, \mathrm{x} 1)$ in Table 12$)$. Thus, in this case,

Table 11 Electricity consumption of ventilation fans and saving potential of VAV scenarios in Helsinki cases

\begin{tabular}{|c|c|c|c|c|}
\hline Scenario & $\begin{array}{l}\text { Constant } \\
\text { setback }\end{array}$ & $\begin{array}{l}\text { Fixed } \\
\text { setback }\end{array}$ & $\begin{array}{l}\text { People's } \\
\text { behaviors }\end{array}$ & $\begin{array}{l}\mathrm{CO}_{2} \\
\text { controlled }\end{array}$ \\
\hline Fan electricity $(\mathrm{kWh})$ & 1854 & 1246 & 1264 & 499 \\
\hline $\begin{array}{l}\text { Saving compared to } \\
\text { "no setback" } \\
\text { scenario }\end{array}$ & - & $-33 \%$ & $-32 \%$ & $-73 \%$ \\
\hline
\end{tabular}

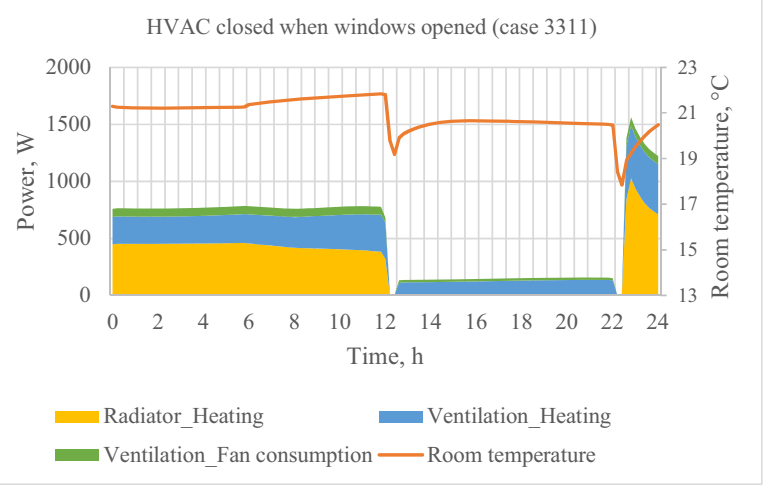

heating and ventilation setback according to people's presence and HVAC turned off when windows are opened (case 3311 - right). Presented day is January 20

adopting an intelligent control mode ensures a major reduction of heating demand than a fixed control mode.

Hence, two opposite considerations have been drawn for Helsinki and Milan cases. It has to be clarified that in both cities, there are some time periods within cases $\mathrm{x} 2$ (HVAC-fixed control mode) when spaces are heated although there are no occupants and no internal loads. Therefore, people do not contribute with their natural heat gain to heating up the room. The discrepancy stands in mechanical ventilation (AHU) use, which is used in Helsinki, but not in Milan. The AHU runs longer time when intelligent HVAC control based on people's presence is adopted than when fixed HVAC control mode is used. AHU energy consumptions counterbalance the benefits achieved by the intelligent HVAC control.

Similar order of results as for Milan has been achieved for Helsinki, assessing these cases considering only heating temperature setback (no mechanical ventilation).

Besides intelligent solutions tailored on people's presence, also intelligent solutions based on $\mathrm{CO}_{2}$ concentration can be adopted for reducing heating energy demand. The analyzed cases consider set point to setback indoor temperature transition time tailored on people's presence, while ventilation airflow volumes are $\mathrm{CO}_{2}$ controlled (referred as to intelligent HVAC control 2; Table 10).

The use of such intelligent solutions ensures a $60 \%$ reduction of heating demand for Helsinki (for details refer to $\Delta(\mathrm{x} 4, \mathrm{x} 1)$ in Table 12). These cases have not been simulated for Milan, as the mechanical ventilation is not considered for this location. Therefore, according to literature findings, the use of intelligent HVAC 
Table 12 Variation of heating demand of different HVAC control modes with respect to constant HVAC control mode (x1)

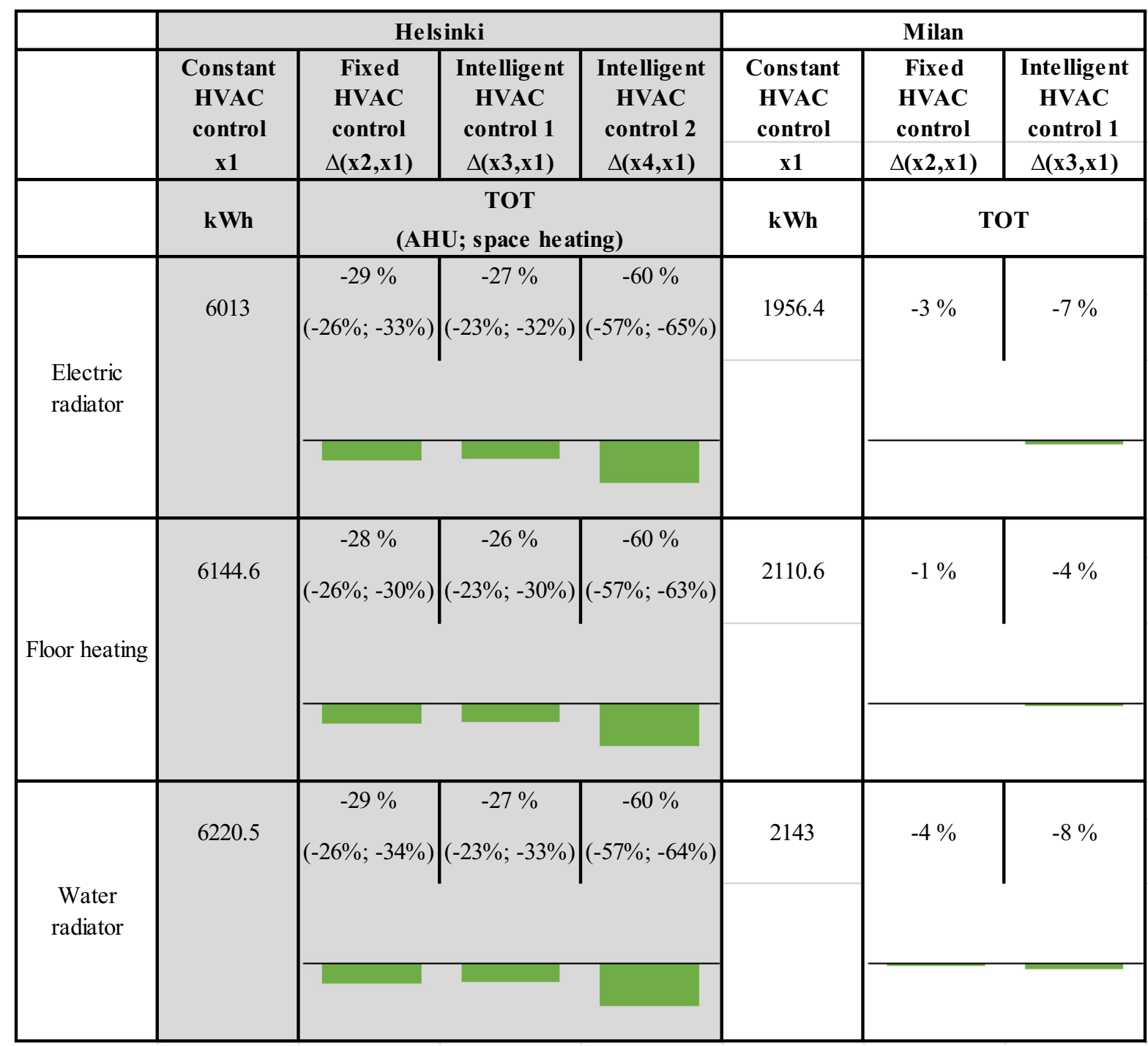

control for keeping $\mathrm{CO}_{2}$ concentration under certain level is promising as a mean of decreasing building heating demand.

As mentioned above, the influence of opening windows combined to different control modes have been also considered. The effect of opening windows at fixed times has been also assessed when HVAC intelligent solutions are installed. As regards Helsinki, HVAC intelligent solutions based on people's presence ensure a $44 \%$ increment of heating energy demand (for further information refer to $\Delta(\mathrm{x} 31, \mathrm{x} 3)$ in Table 13$)$, while intelligent solutions based on $\mathrm{CO}_{2}$ concentration are responsible of an heating energy demand increment of
$70 \%$ (for further information refer to $\Delta(\mathrm{x} 41, \mathrm{x} 4)$ in Table 13). As regard Milan cases, when HVAC intelligent solutions based on people's presence are used, opening of windows causes a $78 \%$ increase of the heating demand (for further information refer to $\Delta(\mathrm{x} 31, \mathrm{x} 3)$ in Table 13).

It is interesting to notice that in Helsinki, opening of windows greatly affects the heating demand when intelligent HVAC solutions based on $\mathrm{CO}_{2}$ concentration are adopted. Consequently, attention has to be paid when using these solutions. Indeed, the positive impact of these ICT solutions can be reduced if people open windows for a relatively short time. On the other hand, 
Table 13 Variation of heating demand of different HVAC control modes coupled with people window opening behaviors with respect to relative HVAC control modes

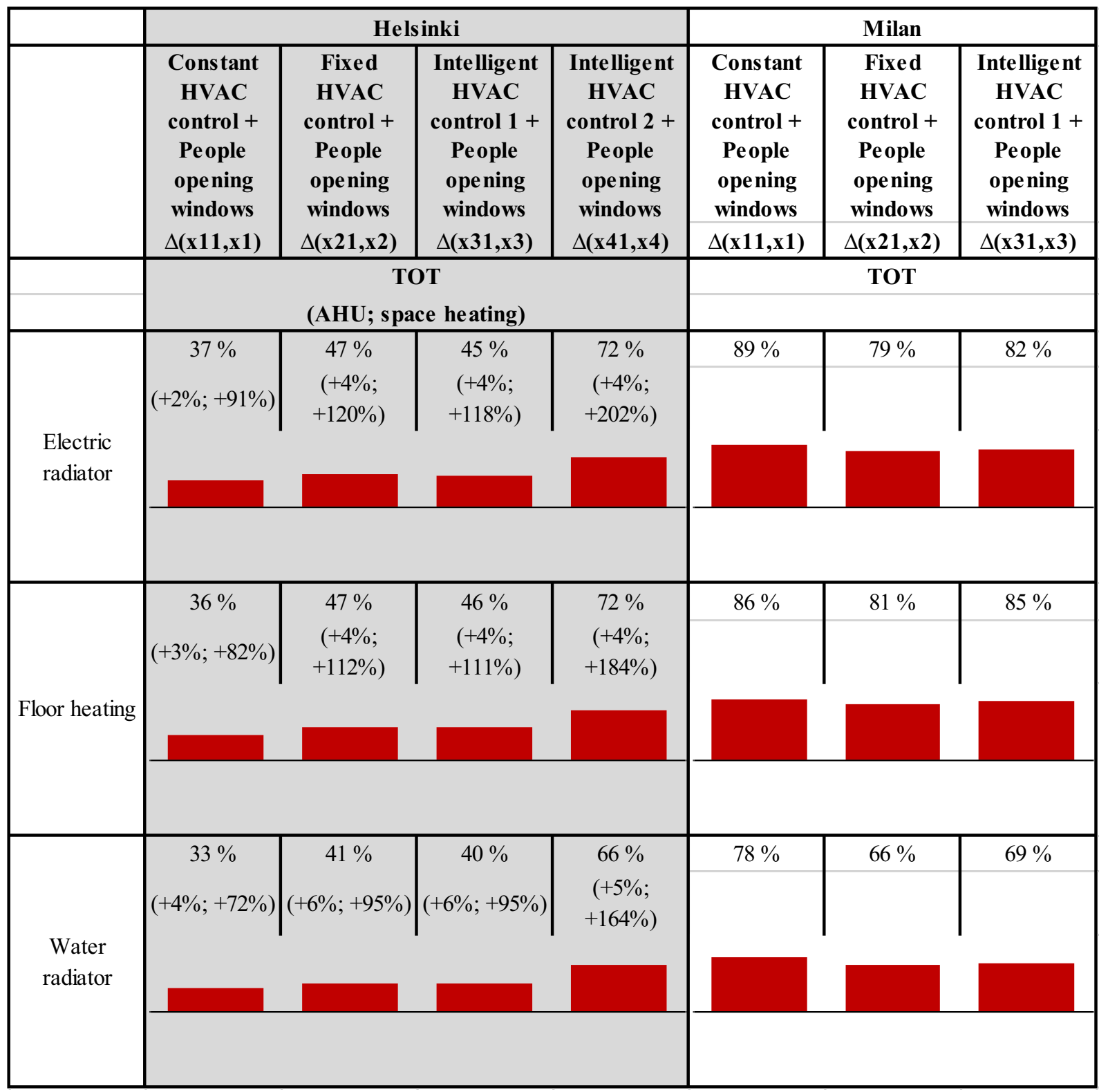

opening of windows moderately affects heating demand when a constant control is adopted. An intermediate increment of heating demand is recorded in the case of both fixed and intelligent (tailored on people's presence) HVAC controls. In all the cases, the heating demand increments affect especially the space heating. Indeed, when the intelligent control is based on people's presence and people open windows (case $\times 31$ described in Table 10), the ventilation system still works contributing to heating the room. Instead, when ventilation is intelligently controlled according to measured $\mathrm{CO}_{2}$ concentration (case $\mathrm{x} 41$ described in Table 10), ventilation does not contribute to space heating (meaning that ventilation system does not work) because $\mathrm{CO}_{2}$ levels are already low due to airflows through the windows.

It is important to point out that results presented in Table 13 can be misleading, because each case is compared to its relative baseline HVAC control mode case 
(i.e., case $\mathrm{x} 31$ is compared to case $\mathrm{x} 3$ and case $\mathrm{x} 41$ is compared to case $x 4$ ). Therefore, in order to evaluate the absolute impact of different HVAC control modes when people open windows, results have been rearranged in Table 14 assuming a single base case: constant HVAC control mode with windows always closed (case $\mathrm{x} 1$ ).

As regard Helsinki cases and comparing cases xyl with the case $\mathrm{x} 1$, if people open windows and the HVAC adopts a constant control mode, the heating energy demand increases by $35 \%$ (for details refer to $\Delta(\mathrm{x} 11, \mathrm{x} 1)$ in Table 14). A moderate increment is recorded if people open windows and HVAC adopts fixed or intelligent (based on people's presence) controls (respectively, a $4 \%$ and a $5 \%$ increase, referring to $\Delta(\mathrm{x} 21, \mathrm{x} 1)$ and $\Delta(\mathrm{x} 31, \mathrm{x} 1)$ in Table 14$)$. Instead, a $32 \%$ reduction is registered if people open windows for a short time every day and the HVAC adopts an intelligent control based on $\mathrm{CO}_{2}$ concentration (for details refer to $\Delta(\mathrm{x} 41, \mathrm{x} 1)$ in Table 14$)$. A reduction is recorded in this case because the intelligent HVAC case has been compared to the case where HVAC operations are constant. Indeed, the beneficial effect of the $\mathrm{CO}_{2}$-based intelligent HVAC control is still dominant even if occupants open windows at fixed times compared to the heating energy demand of the case where indoor air temperature and mechanical ventilation airflow rate set points are constant throughout the time. Thus, comparing cases with different HVAC control modes when people open windows to the case with a constant control and windows always closed, the most promising result is reached by the intelligent control based on $\mathrm{CO}_{2}$ concentration.

As regards Milan, opening windows causes a $84 \%$ heating demand increment with a constant control, a $71 \%$ increment with a fixed control, and a $67 \%$ increment with an intelligent control based on people's presence if such cases are compared to the case with a constant control and windows always closed (for details, refer to $\Delta$ (xy1,xy) in Table 14).

By comparing results achieved in Helsinki and Milan (Table 14), the effect of opening windows is more visible in mild climate conditions. Two are the reasons: the lower heating demand of Milan cases with windows closed compared with the corresponding cases in Helsinki and the longer opening period of windows.

The chance of controlling the opening of windows based on measured levels of $\mathrm{CO}_{2}$ concentration (and not based on people behaviors) has been also considered (Table 15). For Helsinki cases, only the case with fixed HVAC control modes (case x22, described in Table 10) 
Table 15 Variation of heating demand of different HVAC control modes coupled with opening windows according to $\mathrm{CO}_{2}$ concentration with respect to relative HVAC control modes

\begin{tabular}{|c|c|c|c|c|}
\hline & \multirow{2}{*}{$\begin{array}{l}\text { Helsinki } \\
\text { Fixed HVAC } \\
\text { control }+\mathrm{CO}_{2} \\
\text { opening windows } \\
\Delta(\mathrm{x} 22, \mathrm{x} 2) \\
\text { TOT } \\
\text { (AHU; space heating) }(\%)\end{array}$} & \multicolumn{3}{|l|}{ Milan } \\
\hline & & $\begin{array}{l}\text { Constant HVAC } \\
\text { control }+\mathrm{CO}_{2} \\
\text { opening windows } \\
\Delta(\mathrm{x} 12, \mathrm{x} 1) \\
\text { TOT }(\%)\end{array}$ & $\begin{array}{l}\text { Fixed HVAC } \\
\text { control }+\mathrm{CO}_{2} \\
\text { opening windows } \\
\Delta(\mathrm{x} 22, \mathrm{x} 2)\end{array}$ & $\begin{array}{l}\text { Intelligent } \mathrm{HVAC} \\
\text { control } 1+\mathrm{CO}_{2} \\
\text { opening windows } \\
\Delta(\times \times 32, \times 3)\end{array}$ \\
\hline Electric radiator & $+10(+2 ;+25)$ & +21 & +22 & +23 \\
\hline Floor heating & $+11(+2 ;+24)$ & +20 & +19 & +21 \\
\hline Water radiator & $+10(+2 ;+21)$ & +19 & +18 & +20 \\
\hline
\end{tabular}

has been analyzed. There is no need of applying such window control to the other cases as the mechanical ventilation keeps adequate $\mathrm{CO}_{2}$ levels in both constant and intelligent control cases.

Only a $10 \%$ increase has been recorded when windows are opened according to $\mathrm{CO}_{2}$ levels (for details refer to $\Delta(\mathrm{x} 22, \mathrm{x} 2)$ in Table 15$)$. This value is significantly lower than the increment registered when windows are opened according to people behaviors (for details refer to $\Delta(\mathrm{x} 21, \mathrm{x} 2)$ in Table 13$)$.

Obviously, opening of windows increases the heating demand also in Milan cases. Nevertheless, the increment is greatly limited when opening of windows is $\mathrm{CO}_{2}$ controlled (Table 15) with respect to the case when people open windows at fixed times (Table 13). Indeed, heating demand increases $20 \%$ when constant HVAC control mode is adopted if people open windows in accordance with $\mathrm{CO}_{2}$ concentration levels $(\Delta(\mathrm{x} 12, \mathrm{x} 1)$ in Table 15), while heating demand increases $84 \%$ if people open windows at fixed times $(\Delta(\mathrm{x} 11, \mathrm{x} 1)$ in Table 13). In case the HVAC has a fixed control, opening of windows according to $\mathrm{CO}_{2}$ levels brings the heating energy demand up $20 \%$ and $21 \%$ if HVAC intelligent solutions based on people's presence $(\Delta(\mathrm{x} 22, \mathrm{x} 2)$ and $\Delta(\mathrm{x} 32, \mathrm{x} 3)$ in Table 15$)$ are adopted.

The presence of the mechanical ventilation, as for Helsinki cases, drastically reduces the effect of opening windows on the heating energy demand. Windows are barely opened as $\mathrm{CO}_{2}$ levels are below the assumed $\mathrm{CO}_{2}$ concentration threshold. On the contrary, if mechanical ventilation is not adopted (as in Milan cases), windows are often opened, since $\mathrm{CO}_{2}$ level exceeds the assumed $\mathrm{CO}_{2}$ concentration threshold. This explains the difference between Milan (an average increment of heating demand of $20 \%$ for $\Delta(\mathrm{x} 22, \mathrm{x} 2)$ in Table 15$)$ and Helsinki cases (an average increment of heating demand of $10 \%$ for $\Delta(\mathrm{x} 22, \mathrm{x} 2)$ in Table 15$)$.

Thus, supporting people by means of intelligent ICTdriven solutions, which advise them when windows should be opened or closed according to indoor $\mathrm{CO}_{2}$ concentration levels, would be effective for reducing heating energy demand, if people are used to open windows for concerns about health effects of poor indoor conditions.

Table 16 Variation of heating demand of different HVAC control modes coupled with opening windows according to $\mathrm{CO}_{2}$ concentration with respect to the same control modes coupled with opening windows tailored on people's presence

\begin{tabular}{|c|c|c|c|c|}
\hline & \multirow{2}{*}{$\begin{array}{l}\text { Helsinki } \\
\text { Fixed HVAC control }+ \\
\mathrm{CO}_{2} \text { opening windows } \\
\Delta(\mathrm{x} 22, \mathrm{x} 21) \\
\text { TOT (AHU; space heating) }(\%)\end{array}$} & \multicolumn{3}{|l|}{ Milan } \\
\hline & & $\begin{array}{l}\text { Constant HVAC control }+ \\
\mathrm{CO}_{2} \text { opening windows } \\
\Delta(\mathrm{x} 12, \mathrm{x} 11) \\
\text { TOT }(\%)\end{array}$ & $\begin{array}{l}\text { Fixed HVAC control }+ \\
\mathrm{CO}_{2} \text { opening windows } \\
\Delta(\mathrm{x} 22, \mathrm{x} 21)\end{array}$ & $\begin{array}{l}\text { Intelligent HVAC control } \\
1+\mathrm{CO}_{2} \text { opening windows } \\
\Delta(\mathrm{x} 32, \mathrm{x} 31)\end{array}$ \\
\hline Electric radiator & $-25(-2 ;-43)$ & -36 & -32 & -33 \\
\hline Floor heating & $-25(-2 ;-42)$ & -36 & -34 & -35 \\
\hline Water radiator & $-22(-4 ;-38)$ & -33 & -29 & -29 \\
\hline
\end{tabular}




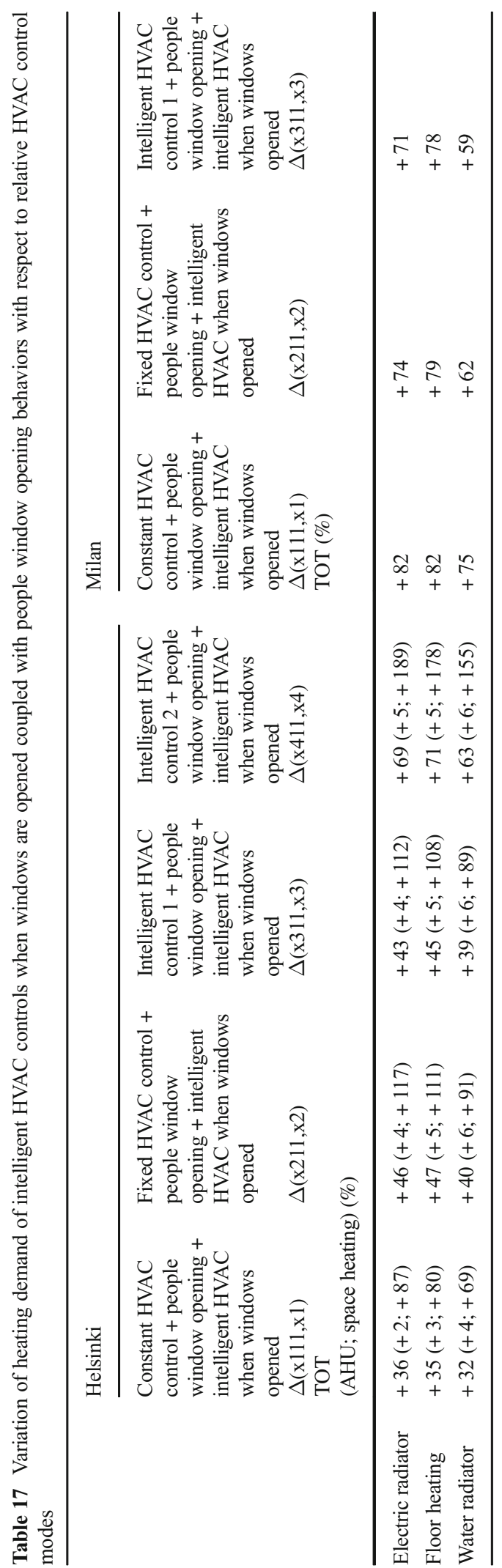

To understand the different impacts on heating energy demand in case windows are opened by people without having a concrete understanding of the indoor conditions and in case people are supported by intelligent ICT-driven solution, which advises them when windows should be opened or closed according to indoor $\mathrm{CO}_{2}$ concentration levels, cases xy1 and xy 2 have been compared (for details refer to $z=1$ and $z=2$ in Table 9). In Helsinki, the adoption of such intelligent ICT-driven solution brings the heating energy demand down by about $24 \%$ compared to the other abovementioned case (windows are opened at fixed times by people, for details refer to $\Delta(\mathrm{x} 22, \mathrm{x} 21)$ in Table 16). In Milan, the adoption of such intelligent ICT-driven solution brings down the heating energy demand by $35 \%$ if constant HVAC control mode is adopted (for details refer to $\Delta(\mathrm{x} 12, \mathrm{x} 11)$ in Table 16$)$ and by $32 \%$ if both fixed HVAC control and intelligent HVAC control modes are used (for details, refer to $\Delta(\mathrm{x} 22, \mathrm{x} 21)$ and $\Delta(\mathrm{x} 32, \mathrm{x} 31)$ in Table 16$)$.

Another intelligent control that can be applied to HVAC systems allows closing the heating system when windows are opened (intelligent HVAC-window control). However, according to simulations, closing the HVAC system when windows are opened does not noticeably reduce the building heating demand. Indeed, in order to consider the influence of this intelligent control, cases $\mathrm{x} 11$ and $\mathrm{x} 111$ can be compared. These two cases consider a constant HVAC control mode with window opened by people at fixed times. For the sake of comparison, it is useful to recall that in Helsinki, when people open the windows a $35 \%$ increase is registered (for details refer to $\Delta(\mathrm{x} 11, \mathrm{x} 1)$ in Table 13). If the HVAC has an intelligent window control, the heating demand increases $34 \%$ (for details refer to $\Delta(\mathrm{x} 111, \mathrm{x} 1)$ in Table 17$)$. As shown, the difference between the two cases is not significant. However, it is worth to highlight that results of the latter case are influenced by the assumptions made about the window opening time. Obviously, if windows stay open for long-time, intelligent HVAC solutions, which shut off the HVAC system when windows are opened, have a relevant impact on building heating reduction. The adoption of such an intelligent control is not significant even in the cases of both fixed and intelligent (both tailored on people's presence and $\mathrm{CO}_{2}$ levels) HVAC controls. On the other hand, as regards Milan, a relatively bigger difference is recorded if the HVAC adopts such control when people open windows at fixed times.

Turning off the HVAC system when people open windows reduces the heating energy demand of $5 \%$ if 
Table 18 Variation of heating demand of intelligent HVAC controls when windows are opened coupled with $\mathrm{CO}_{2}$ window opening behaviors with respect to relative HVAC control modes

\begin{tabular}{|c|c|c|c|c|}
\hline & \multirow{2}{*}{$\begin{array}{l}\text { Helsinki } \\
\text { Fixed HVAC control + } \\
\mathrm{CO}_{2} \text { opening windows + } \\
\text { intelligent HVAC when } \\
\text { windows opened } \\
\Delta(\mathrm{x} 221, \mathrm{x} 2) \\
\text { TOT }(\mathrm{AHU} ; \text { space } \\
\text { heating }(\%)\end{array}$} & \multicolumn{3}{|l|}{ Milan } \\
\hline & & $\begin{array}{l}\text { Constant HVAC control + } \\
\mathrm{CO}_{2} \text { opening windows }+ \\
\text { intelligent HVAC when } \\
\text { windows opened } \\
\Delta(\mathrm{x} 121, \mathrm{x} 1) \\
\text { TOT }(\%)\end{array}$ & $\begin{array}{l}\text { Fixed HVAC control }+ \\
\mathrm{CO}_{2} \text { opening windows }+ \\
\text { intelligent HVAC when } \\
\text { windows opened } \\
\Delta(\mathrm{x} 221, \mathrm{x} 2)\end{array}$ & $\begin{array}{l}\text { Intelligent HVAC control } \\
1+\mathrm{CO}_{2} \text { opening windows }+ \\
\text { intelligent HVAC when } \\
\text { windows opened } \\
\Delta(\mathrm{x} 321, \mathrm{x} 3)\end{array}$ \\
\hline Electric radiator & $+11(+2 ;+26)$ & +18 & +14 & +9 \\
\hline Floor heating & $+10(+2 ;+24)$ & +21 & +21 & +21 \\
\hline Water radiator & $+10(+2 ;+21)$ & +15 & +11 & +3 \\
\hline
\end{tabular}

the HVAC adopts a constant control mode, of $4 \%$ if a fixed HVAC control is used and of 9\% if intelligent HVAC control based on people's presence is adopted (respectively, comparing $\Delta(\mathrm{xy} 1, \mathrm{xy})$ of Table 13 and $\Delta$ (xy11,xy) of Table 17).

Applying such intelligent HVAC control when windows are opened according to $\mathrm{CO}_{2}$ levels leads to similar results (Table 18).

Particularly, considering cold climate conditions (e.g., refer to Helsinki), closing the HVAC system when windows are opened does not bring considerable effects. In fact, no benefits are registered by comparing cases $\mathrm{x} 221$ and $\mathrm{x} 22$ (for details refer to $\Delta(\mathrm{x} 221, \mathrm{x} 2)$ in Table 18 and $\Delta(\mathrm{x} 22, \mathrm{x} 2)$ in Table 15$)$.

Instead, in mild climate conditions (e.g., refer to Milan), great benefits in terms of heating demand reduction are achieved with HVAC systems with a low thermal mass (e.g., electric and water radiator). Negligible benefits are registered with floor heating system, considering its high thermal mass (for details results on the line of floor heating presented in Table 18 and in Table 15 should be compared). The effect of turning off the HVAC when windows are opened according to $\mathrm{CO}_{2}$ levels is significant especially when HVAC operations are tailored based on people's presence. In this case, this intelligent control brings up the heating energy demand by $11 \%$ (for details refer to $\Delta(x 321, x 3)$ in Table 18 ), while without applying such intelligent control, heating demand increases $21 \%$ (for details refer to $\Delta(\mathrm{x} 32, \mathrm{x} 3)$ in Table 15$)$. If HVAC has a constant control mode, the heating energy demand increases $18 \%$ with intelligent HVAC-window control, instead of $20 \%$ without such control (refer to $\Delta(\mathrm{x} 121, \mathrm{x} 1)$ in Table 18 and $\Delta(\mathrm{x} 12, \mathrm{x} 1)$ in Table 15$)$. If HVAC has a fixed control mode, the heating energy demand increases $15 \%$ with intelligent HVAC-window control, instead of $20 \%$ without such control (refer to $\Delta(\mathrm{x} 221, \mathrm{x} 2)$ in Table 18 and $\Delta(\mathrm{x} 22, \mathrm{x} 2)$ in Table 15$).$ The effect of turning off the HVAC system when windows are opened can be appreciated also in Fig. 9, where durational curves has been analyzed for three cases (case 33, 331, and 3311).

Obviously, when people open windows at fixed times (case 331), the indoor air temperature reduces compared to the case with windows always closed (case 33). Moreover, turning off the HVAC system when windows are opened (case 3311) further reduces the indoor air temperature.

In case 331, when windows are opened according to people's behaviors, considering $22^{\circ} \mathrm{C}$ as a threshold, the indoor air temperature is below this threshold for half of the time when rooms are occupied and half of the time when rooms are unoccupied (Fig. 9). Instead, if $20{ }^{\circ} \mathrm{C}$ was considered as a threshold, indoor air temperature is below it for $90 \mathrm{~h} /$ year $(80 \mathrm{~h}$ during occupied periods and $10 \mathrm{~h}$ during unoccupied periods). Only $5.5 \mathrm{~h} /$ year, the indoor air temperature is below $18{ }^{\circ} \mathrm{C}$, during occupied periods.

Instead, when windows are opened according to measured $\mathrm{CO}_{2}$ levels (case 332), room temperature stays below $22^{\circ} \mathrm{C} 160 \mathrm{~h}$ per year $(35 \mathrm{~h}$ during occupied periods and $125 \mathrm{~h}$ during unoccupied periods), while it never goes below $20^{\circ} \mathrm{C}$ or $18{ }^{\circ} \mathrm{C}$.

Thus, if people would be supported by intelligent ICT-driven solutions, which advise them when windows should be opened or closed according to indoor $\mathrm{CO}_{2}$ concentration levels, satisfying indoor conditions could be guaranteed. 
Fig. 9 Durational curves of the cases with water radiator and intelligent HVAC control 1 (case 33) + people window opening (case 331) + intelligent HVAC when windows opened (case 3311) in Helsinki
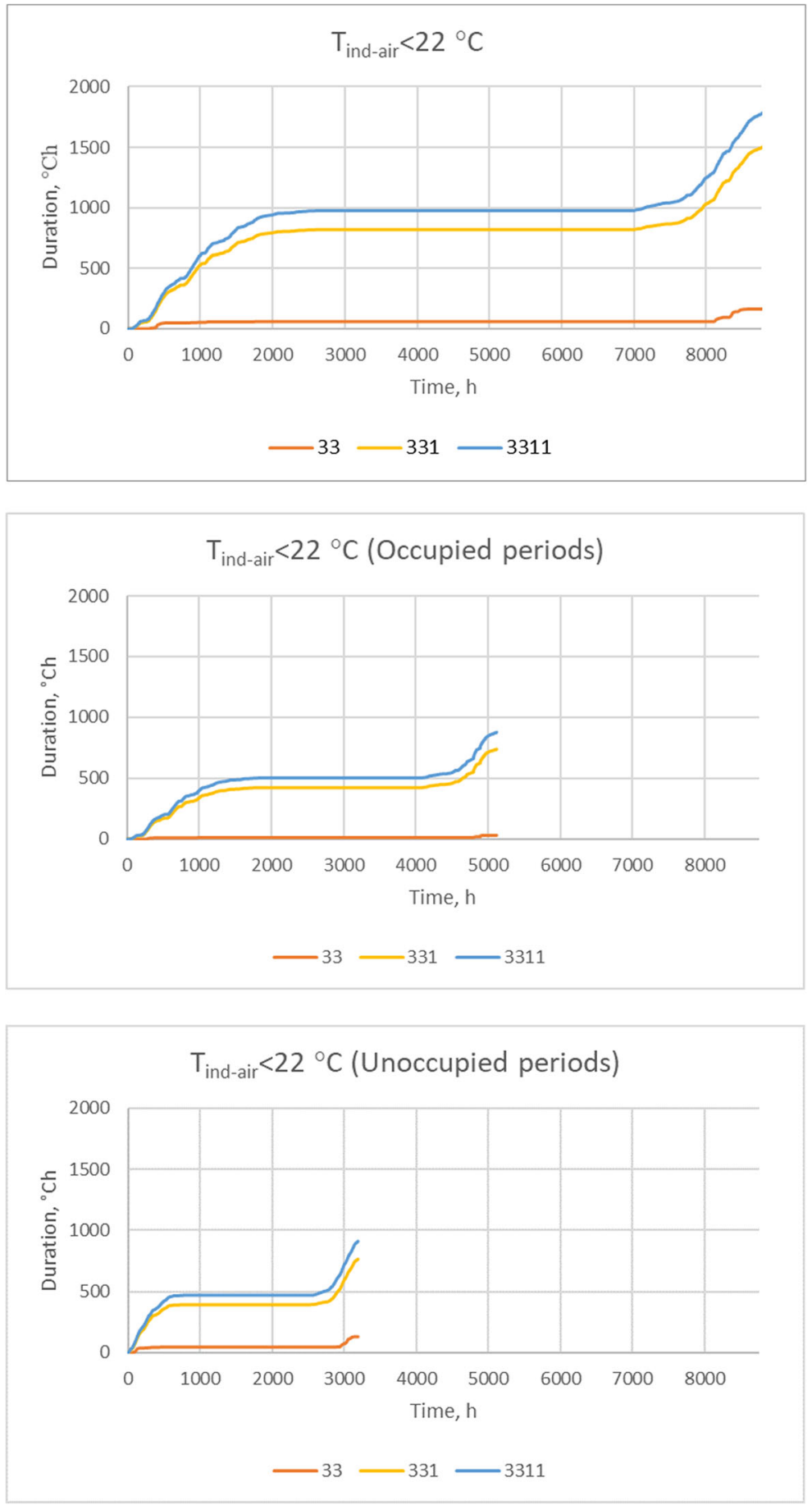

\section{Discussion}

Considering the great influence of people with their everyday actions on energy consumption, specific people behaviors have been assessed for evaluating their impact on heating demand. Four intelligent ICT-driven solutions (based on people's presence and $\mathrm{CO}_{2}$ concentration), meant for tackling such behaviors, have been evaluated. Finally, benefits, in terms of potential heating demand 
reduction coming from the use of such solutions, have been highlighted.

Results of the presented research show that adopting a fixed HVAC control mode (fixed set point to setback indoor temperature transition time and airflow volumes fixed schedule) ensures a reduction of the heating demand compared to a constant control mode (indoor temperature set point and airflow rates constant all the time). The reduction is higher in cold climates than in mild climates.

When both constant and fixed control modes are adopted, people who open windows greatly increase the heating demand. Indeed, if windows are opened for a short time (windows are opened twice a day for $30 \mathrm{~min}$ ), the heating demand can even double in cold climate conditions. Opening of windows has a larger impact in mild climates, increasing the heating demand by about $80 \%$ in case of both constant and fixed HVAC control modes.

Nevertheless, intelligent ICT-driven solutions can support people managing HVAC settings and, even, opening of windows, especially if people are used to open windows for concerns about health effects of poor indoor conditions.

Among them, the use of an intelligent HVAC control mode able to tailor both set point to setback indoor temperature transition time and airflow volumes according to actual people's presence can greatly reduce the heating energy demand, contemporarily easing the burden of setting precise HVAC operation schedules. Indeed, this control allows automatically decreasing the set point temperature to the setback temperature and turning ventilation to the minimum flow rate when people are not at home.

In these cases, a rational use of energy is ensured, as the HVAC system works according to the real people's presence. The effect of these solutions is more significant in cold than in mild climate conditions, since mechanical ventilation consumption is very sensitive to people's presence. However, if the fixed control is properly set in place, the adoption of such intelligent solution has not much sense.

Great benefits, in terms of heating energy demand reduction, can also be achieved when intelligent solutions are based on measured $\mathrm{CO}_{2}$ levels. Results show that it is possible even to halve the heating demand compared to the case with constant control.

Even when intelligent HVAC solutions based on tracking people's presence or $\mathrm{CO}_{2}$ levels are adopted, people who open windows regularly drastically increase the heating demand. Therefore, attention has to be paid when using these solutions considering that the positive impact of these intelligent solutions can be reduced when windows are opened, even for short time. Thus, solutions that prevent opening of windows for meaningful reasons should be implemented when such intelligent ICT-driven solutions are in place.

In case the HVAC does not handle properly $\mathrm{CO}_{2}$ concentration levels and people are used to open windows for concerns about health effects of poor indoor condition, building heating demand can be reduced supporting users with intelligent ICT-driven solutions for advising them when windows should be opened or closed according to $\mathrm{CO}_{2}$ concentration levels. The effect can be appreciated especially in mild climate conditions, where the mechanical ventilation is not considered. It has to be mentioned that authors assumed that people would meticulously comply with the instructions received by such intelligent ICT-driven solutions. In reallife conditions, most probably people would not comply very scrupulously with the instructions received.

For reducing the effect of windows opening on heating demand, also an intelligent HVAC-window control can be considered. This control is able to turn off the HVAC when windows are opened. However, results show that there is not significant effect when such intelligent solutions are adopted in cold climate conditions. On the other hand, in mild climate conditions, especially when heating systems with low thermal masses are installed, this intelligent solution is promising.

This work follows a previous research (Pasini et al. 2017), where authors have defined the use of energy recipes (instructions and rules) as promising method to tackle energy hungry behaviors and turn them into energy rational behaviors for reaching energy savings. These energy recipes will be made available to users through a platform developed within a project, namely Evidence, as presented in Fig. 10.

The results presented in this paper will be used for creating energy recipes in order to support building occupants in reducing the heating demand.

Along the research path, authors noted that no indications are generally provided for informing users if energy is efficiently and effectively used. Therefore, a possible continuation of this research could focus on proposing an indicator estimating if energy is efficiently and effectively used (simplifying, using energy for heating up the room when people are occupying it). In order to develop this indicator, not only energy demand 


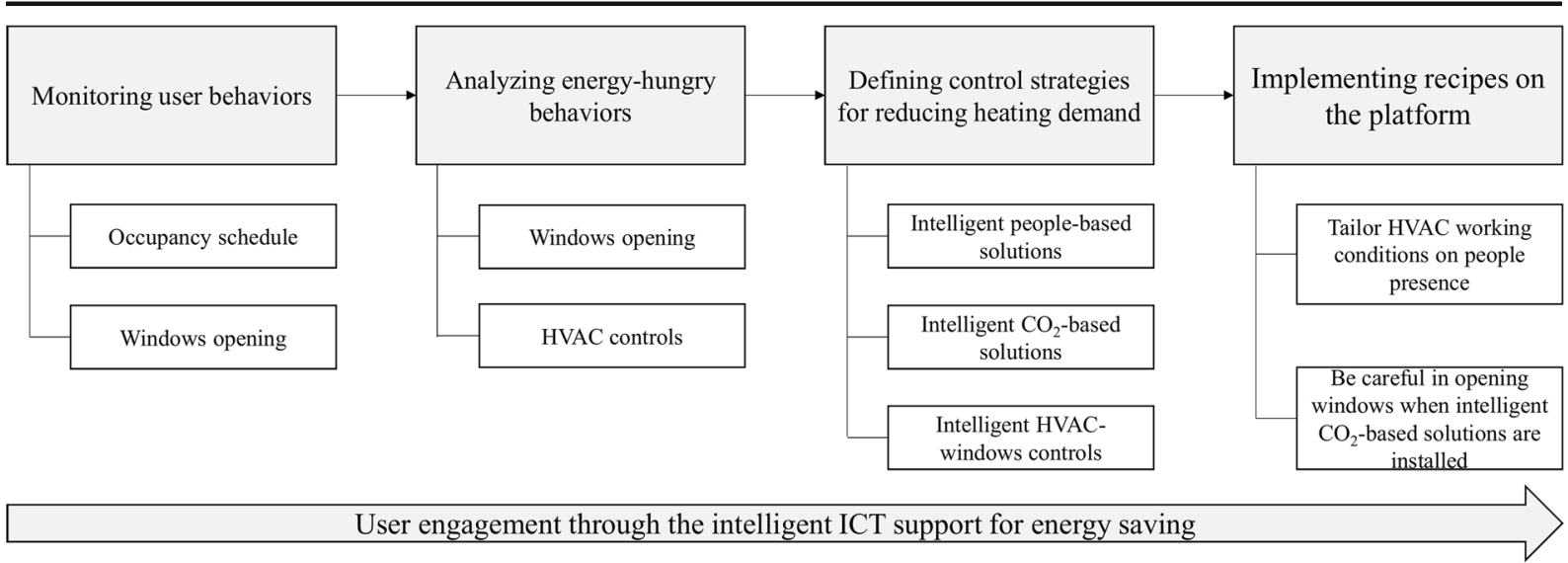

Fig. 10 Framework of the developed research within evidence project

should be taken into account but also indoor comfort conditions should be considered (e.g., through PMV and PPD comfort indexes). Hence, perceived comfort conditions should be correlated with energy consumption, for ensuring adequate indoor conditions, and also with period of occupancy of the building.

\section{Conclusions}

ICT solutions are widely recognized as instrumental in obtaining energy savings in building operation. In order to evaluate and quantify the effect of these solutions for reducing heating demand, the paper focuses on the use of existing ICT devices for tackling people energy hungry behaviors, with regard to HVAC settings and window opening behaviors. Both aspects, if not properly handled by building occupants, can result into energy hungry behaviors.

Therefore, the paper proposes suggestions to be adopted by building occupants, outlining the benefits achievable through an enhanced use of intelligent ICT solutions for reducing energy demand based on the results of simulations. Two different localities, Helsinki and Milan, have been considered as representative of cold and mild European climate conditions. Main results outline that, in case buildings have mechanical ventilation systems, adopting ICT-driven intelligent solutions for setting heating setback and indoor set point temperatures and for controlling the mechanical ventilation according to actual people's presence and $\mathrm{CO}_{2}$ levels leads to considerable reductions of energy demand, especially in Helsinki. On the other hand, if mechanical ventilation does not work properly or is missing, adopting ICT-driven intelligent solutions for advising building users when windows should be opened or closed according to sensed $\mathrm{CO}_{2}$ levels can potentially decrease building energy demand. Obviously, the more people comply with instructions, given by ICT-driven intelligent solutions, the higher the energy savings are. This is relevant especially in Milan.

For what concerns the adoption of intelligent HVACwindow controls, which enable to turn off the HVAC when windows are opened for relatively short time (30 min in Helsinki and $1 \mathrm{~h}$ in Milan), they do not ensure a significant effect in Helsinki, while this solution is promising in Milan, especially when heating systems, with low thermal mass, are installed. Finally, it has to be emphasized that behavioral change activities are also needed to pave the way for introducing new technologies in people homes. The natural evolution of ICT intelligent solutions alone is not enough to ensure a successful implementation of these if people are not ready to receive them.

Acknowledgments Open access funding provided by Technical Research Centre of Finland (VTT). The authors wants to express their gratitude to both Aalto and Helsinki University Digital Content Communities research team and, particularly, to Prof. Giulio Jacucci, who is currently leading EVIDENCE project, and Dr. Mrs. Tarja Häkkinen for her concrete support.

Funding information The work reported upon here has been supported by Evidence project "Evaluating Smart Incentives in Social Formation of Energy Choices," funded by the Academy of Finland (decision number 286648).

\section{Compliance with ethical standards}

Conflict of interest The authors declare that they have no conflict of interest. 


\section{Appendix}

Table 19 Occupancy schedule based on data collected on a real case study

\begin{tabular}{|c|c|c|c|c|c|}
\hline & \multicolumn{2}{|l|}{ Mon } & \multicolumn{2}{|c|}{ Tue } & Wed \\
\hline Standard working week & \multicolumn{2}{|c|}{$00.00-09.30 ; 17.00-24.00$} & \multicolumn{2}{|c|}{$00.00-08.30 ; 18.00-24.00$} & $00.00-09.30 ; 19.00-24.00$ \\
\hline Business trip & \multicolumn{2}{|l|}{$00.00-11.00$} & \multicolumn{2}{|c|}{-} & $16.30-24.00$ \\
\hline $\begin{array}{l}\text { Occupants exit only } \\
\text { during the afternoon }\end{array}$ & \multicolumn{2}{|c|}{$00.00-15.30 ; 23.00-24.00$} & \multicolumn{2}{|c|}{$00.00-14.30 ; 23.00-24.00$} & $00.00-14.30 ; 20.00-24.00$ \\
\hline Weekend at home & \multicolumn{2}{|c|}{$00.00-08.30 ; 15.00-24.00$} & \multicolumn{2}{|c|}{$00.00-09.30 ; 16.00-24.00$} & $00.00-15.30 ; 23.00-24.00$ \\
\hline $\begin{array}{l}\text { Standard working week, } \\
\text { with one rest day }\end{array}$ & \multicolumn{2}{|l|}{$00.00-24.00$} & \multicolumn{2}{|c|}{$00.00-09.30 ; 18.00-24.00$} & $00.00-09.30 ; 19.00-24.00$ \\
\hline $\begin{array}{l}\text { Standard working week, } \\
\text { with one night out }\end{array}$ & \multicolumn{2}{|c|}{$00.00-10.00 ; 19.30-24.00$} & \multicolumn{2}{|c|}{$00.00-10.00 ; 20.30-24.00$} & $00.00-09.00 ; 16.30-24.00$ \\
\hline $\begin{array}{l}\text { Standard working week, } \\
\text { with some part-time } \\
\text { working days }\end{array}$ & \multicolumn{2}{|c|}{$00.00-08.30 ; 19.00-24.00$} & \multicolumn{2}{|c|}{$00.00-09.30 ; 17.00-24.00$} & $00.00-08.30 ; 18.00-24.00$ \\
\hline \multirow[t]{2}{*}{ Trip during the weekend } & \multicolumn{2}{|c|}{$00.00-09.30 ; 13.00-24.00$} & \multicolumn{2}{|c|}{$00.00-08.30 ; 13.00-24.00$} & $00.00-09.30 ; 17.00-24.00$ \\
\hline & Thu & \multicolumn{2}{|l|}{ Fri } & Sat & Sun \\
\hline Standard working week & $00.00-09.30 ; 18.00-24.00$ & \multicolumn{2}{|c|}{$00.00-09.30 ; 10.00-24.00$} & $00.00-12.30 ; 17.00-24.00$ & $00.00-14.30 ; 15.00-24.00$ \\
\hline Business trip & $00.00-10.30 ; 18.30-24.00$ & \multicolumn{2}{|c|}{$00.00-09.30 ; 16.30-24.00$} & $00.00-12.30$ & $20.30-24.00$ \\
\hline $\begin{array}{l}\text { Occupants exit only } \\
\text { during the afternoon }\end{array}$ & $00.00-12.30 ; 22.00-24.00$ & \multicolumn{2}{|c|}{$00.00-14.30 ; 20.00-24.00$} & $00.00-17.30 ; 21.00-24.00$ & $00.00-13.30 ; 18.00-24.00$ \\
\hline Weekend at home & $00.00-09.30 ; 17.00-24.00$ & \multicolumn{2}{|c|}{$00.00-12.30 ; 16.00-24.00$} & $00.00-09.30 ; 21.00-24.00$ & $00.00-24.00$ \\
\hline $\begin{array}{l}\text { Standard working week, } \\
\text { with one rest day }\end{array}$ & $00.00-08.30 ; 18.00-24.00$ & \multicolumn{2}{|c|}{$00.00-09.30 ; 19.00-24.00$} & $00.00-12.30 ; 19.00-24.00$ & $00.00-10.30 ; 19.00-24.00$ \\
\hline $\begin{array}{l}\text { Standard working week, } \\
\text { with one night out }\end{array}$ & $00.00-09.00$ & \multicolumn{2}{|c|}{$01.30-24.00$} & $00.00-19.00 ; 19.30-24.00$ & $00.00-08.00 ; 22.30-24.00$ \\
\hline $\begin{array}{l}\text { Standard working week, } \\
\text { with some part-time } \\
\text { working days }\end{array}$ & $00.00-09.30 ; 15.00-24.00$ & \multicolumn{2}{|c|}{$00.00-08.30 ; 15.00-24.00$} & $00.00-13.30 ; 19.30-24.00$ & $00.00-08.00 ; 20.30-24.00$ \\
\hline Trip during the weekend & $00.00-08.30 ; 18.00-24.00$ & \multicolumn{2}{|c|}{$00.00-10.30 ; 17.00-24.00$} & $00.00-11.30$ & - \\
\hline
\end{tabular}

Open Access This article is distributed under the terms of the Creative Commons Attribution 4.0 International License (http:// creativecommons.org/licenses/by/4.0/), which permits unrestricted use, distribution, and reproduction in any medium, provided you give appropriate credit to the original author(s) and the source, provide a link to the Creative Commons license, and indicate if changes were made.

\section{References}

AA.VV. (2010). Classification of indoor environment 2008target values, design guidance, and product requirements.

Andersen, R. V. (2009). Occupant behaviour with regard to control of the indoor environment. http://orbit.dtu. $\mathrm{dk} /$ fedora/objects/orbit:82635/datastreams/file_5044630 /content

Asuntoministeri, J., Vapaavuori, Y.-I., \& Kalliomäki, P. (2010). Rakennusten energiatehokkuus.

Briefing EU Legislation in progress improving energy performance of buildings proposal for a directive of the
European Parliament and of the Council amending Directive 2010/31/EU on the energy performance of buildings. (2017). http://www.europarl.europa. eu/RegData/etudes/BRIE/2017/599299/EPRS_BRI(2017) 599299_EN.pdf

Building performance-simulation Software | EQUA. (n.d.). https://www.equa.se/en/. Accessed 7 December 2017.

Candanedo, J. A., Dehkordi, V. R., Saberi-Derakhtenjani, A., \& Athienitis, A. K. (2015). Near-optimal transition between temperature setpoints for peak load reduction in small buildings. Energy \& Buildings, 87, 123-133. https://doi. org/10.1016/j.enbuild.2014.11.021.

Cao, G., Awbi, H., Yao, R., Fan, Y., Sirén, K., Kosonen, R., \& Zhang, J. J. (2014). A review of the performance of different ventilation and airflow distribution systems in buildings. Building and Environment, 73, 171-186. https://doi. org/10.1016/j.buildenv.2013.12.009.

Cetin, K. S., Tabares-Velasco, P. C., \& Novoselac, A. (2014). Appliance daily energy use in new residential buildings: Use profiles and variation in time-of-use. Energy and Buildings, 84, 716-726. https://doi.org/10.1016/j. enbuild.2014.07.045. 
Cetin, K. S., Manuel, L., \& Novoselac, A. (2016). Effect of technology-enabled time-of-use energy pricing on thermal comfort and energy use in mechanically-conditioned residential buildings in cooling dominated climates. Building and Environment, 96, 118-130. https://doi.org/10.1016/j. buildenv.2015.11.012.

Chenari, B., Dias Carrilho, J., \& Gameiro da Silva, M. (2016). Towards sustainable, energy-efficient and healthy ventilation strategies in buildings: a review. Renewable and Sustainable Energy Reviews, 59, 1426-1447. https://doi.org/10.1016/j. rser.2016.01.074.

Chenari, B., Lamas, F. B., Gaspar, A. R., \& da Silva, M. G. (2017). Simulation of occupancy and CO2-based demand-controlled mechanical ventilation strategies in an office room using EnergyPlus. Energy Procedia, 113, 51-57. https://doi. org/10.1016/j.egypro.2017.04.013.

Climate and energy package-European Commission. (2017). http://ec.europa.eu/clima/policies/strategies/2020/index_en. htm

CORDIS Archive: European Commission: ICT for sustainable growth: projects. (2015). http://cordis.europa.eu/fp7 /ict/sustainable-growth/energy_en.html

D’Oca, S., Fabi, V., Corgnati, S. P., \& Andersen, R. K. (2014). Effect of thermostat and window opening occupant behavior models on energy use in homes. Building Simulation, 7(6), 683-694. https://doi.org/10.1007/s12273-014-0191-6.

D'Oca, S., Corgnati, S., \& Hong, T. (2015). Data mining of occupant behavior in office buildings. Energy Procedia, 78, 585-590. https://doi.org/10.1016/j.egypro.2015.11.022.

Date, J., Athienitis, A. K., \& Fournier, M. (2015). A study of temperature set point strategies for peak power reduction in residential buildings. Energy Procedia, 78, 2130-2135. https://doi.org/10.1016/j.egypro.2015.11.289.

De Wilde, P. (2014). The gap between predicted and measured energy performance of buildings: a framework for investigation. Automation in Construction, 41, 40-49. https://doi. org/10.1016/j.autcon.2014.02.009.

Delzendeh, E., Wu, S., Lee, A., \& Zhou, Y. (2017). The impact of occupants' behaviours on building energy analysis: a research review. Renewable and Sustainable Energy Reviews, 80, 1061-1071, ISSN 1364-0321. https://doi.org/10.1016/j. rser.2017.05.264.

Energy Efficient Buildings. ICT for sustainable growth. EuropaInformation Society. (2017). http://ec.europa.eu/information society/activities/sustainable_growth/buildings/index_en.htm

Energy Strategy_European Commission. (2017). https://ec. europa.eu/energy/en/topics/energy-strategy/2030-energystrategy

Ente Italiano di Normazione. (2014). UNI 11300-1:2014Prestazioni energetiche degli edifici-Determinazione del fabbisogno di energia termica dell'edificio per la climatizzazione estiva ed invernale.

European Commission. Commission recommendation of 10 October 2014 on the data protection impact assessment template for smart grid and smart metering systems (2014/724/EU) (2014). http://eur-lex.europa.eu/legal-content/EN/TXT/?uri= uriserv\%3AOJ.L_.2014.300.01.0063.01.ENG

European Commission. (2016). Communication from the Commission to the European Parliament, the Council, the European economic and social Committee, the Committee of the Regions and the European Investment Bank Clean
Energy For All Europeans. http://eur-lex.europa.eu/legalcontent/EN/TXT/?uri=COM:2016:860:FIN

Eurostat. (2012). Eurostat - data explorer. Land use overview by NUTS 2 regions. http://appsso.eurostat.ec.europa. eu/nui/submitViewTableAction.do

Fabi, V., Andersen, R. V., Corgnati, S., \& Olesen, B. W. (2012). Occupants' window opening behaviour: a literature review of factors influencing occupant behaviour and models. Building and Environment, 58, 188-198. https://doi.org/10.1016/j. buildenv.2012.07.009.

Fabi, V., Andersen, R. V., Corgnati, S. P., \& Olesen, B. W. (2013). A methodology for modelling energy-related human behaviour: application to window opening behaviour in residential buildings. Building Simulation, 6(4), 415-427. https://doi. org/10.1007/s12273-013-0119-6.

Fadzli Haniff, M., Selamat, H., Yusof, R., Buyamin, S., \& Sham Ismail, F. (2013). Review of HVAC scheduling techniques for buildings towards energy-efficient and cost-effective operations. Renewable and Sustainable Energy Reviews, 27, 94-103. https://doi.org/10.1016/j.rser.2013.06.041.

Finnish Energy. (2014). District heating of buildings regulations and guidelines.

Fournier, M., \& Leduc, M.-A. (2014). Study of electrical heating setpoint modulation strategies for residential demand response. In eSim.

Ghahramani, A., Zhang, K., Dutta, K., Yang, Z., \& BecerikGerber, B. (2016). Energy savings from temperature setpoints and deadband: quantifying the influence of building and system properties on savings. Applied Energy, 165, 930942. https://doi.org/10.1016/j.apenergy.2015.12.115.

Gunay, H. B., O’Brien, W., Beausoleil-Morrison, I., Bisaillon, P., \& Shi, Z. (2016). Development and implementation of control-oriented models for terminal heating and cooling units. Energy and Buildings, 121, 78-91. https://doi. org/10.1016/j.enbuild.2016.04.002.

Gupta, M., Intille, S. S., \& Larson, K. (2009). Adding GPS-control to traditional thermostats: an exploration of potential energy savings and design challenges. In International Conference on Pervasive Computing (pp. 95-114).

Hannus, M., Kazi, A. S., \& Zarli, A. (2010). ICT supported energy efficiency in construction.

ICT 4 E2B Forum (2017).

IDA ICE - simulation software | EQUA. (n.d.). http://www.equa. se/en/ida-ice. Accessed 21 July 2017.

Jeong, B., Jeong, J.-W., \& Park, J. S. (2016). Occupant behavior regarding the manual control of windows in residential buildings. Energy and Buildings, 127, 206-216. https://doi. org/10.1016/j.enbuild.2016.05.097.

Johansson, M., Haataja, K., Kolehmainen, M., \& Toivanen, P. (2015). Design of a novel adaptive indoor air quality control for co-learning smart house (pp. 1-10). Cham: Springer. https://doi.org/10.1007/978-3-319-17136-4_1.

Kadtronix. (2016). http://www.kadtronix.com/hsrs.htm

Karjalainen, S. (2007). Why it is difficult to use a simple device: an analysis of a room thermostat. In Human-computer interaction. Interaction design and usability (pp. 544-548). Berlin, Heidelberg: Springer Berlin Heidelberg. https://doi. org/10.1007/978-3-540-73105-4_60.

Karjalainen, S. (2016). Should we design buildings that are less sensitive to occupant behaviour? A simulation study of effects of behaviour and design on office energy consumption. 
Energy Efficiency, 9(6), 1257-1270. https://doi.org/10.1007 /s12053-015-9422-7.

Kleiminger, W., Mattern, F., \& Santini, S. (2014). Predicting household occupancy for smart heating control: a comparative performance analysis of state-of-the-art approaches. Energy and Buildings, 85, 493-505. https://doi.org/10.1016 j.enbuild.2014.09.046.

Kontoleon, K. J., \& Bikas, D. K. (2006). The influence of the zone's indoor temperature settings on the cooling/heating loads for fixed and controlled ventilation. Building and Environment, 41, 75-86. https://doi.org/10.1016/j. buildenv.2005.01.022.

Lee, S., Chon, Y., Kim, Y., Ha, R., \& Cha, H. (2013). Occupancy prediction algorithms for thermostat control systems using mobile devices. IEEE Transactions on Smart Grid, 4(3), 1332-1340. https://doi.org/10.1109/TSG.2013.2247072.

Lu, J., Sookoor, T., Srinivasan, V., Gao, G., Holben, B., Stankovic, J., et al. (2010). The smart thermostat: using occupancy sensors to save energy in homes. Proceedings of ACM SenSys, 55, 211-224. https://doi. org/10.1145/1869983.1870005.

McCoy, A. P., Zhao, D., Ladipo, T., Agee, P., \& Mo, Y. (2018). Comparison of green home energy performance between simulation and observation: a case of Virginia, United States. Journal of Green Building, 13(3), 70-88.

Moon, J. W., \& Han, S.-H. (2011). Thermostat strategies impact on energy consumption in residential buildings. Energy and Buildings, 43(2), 338-346. https://doi.org/10.1016/j. enbuild.2010.09.024.

Moon, J. W., \& Jung, S. K. (2016). Development of a thermal control algorithm using artificial neural network models for improved thermal comfort and energy efficiency in accommodation buildings. Applied Thermal Engineering, 103, 1135-1144. https://doi. org/10.1016/j.applthermaleng.2016.05.002.

$\mathrm{Net}$ a t mo. ( 2016$)$. h t t p s:// w w w net a t mo. com/product/energy/thermostat

Paris Agreement - European Commission. (2015). http://ec. e u r o p a .

eu/clima/policies/international/negotiations/paris/index_en. htm

Pasini, D., Reda, F., \& Häkkinen, T. (2017). User engaging practices for energy saving in buildings: critical review and new enhanced procedure. Energy \& Buildings, 148, 74-88. https://doi.org/10.1016/j.enbuild.2017.05.010.

Pritoni, M., Woolley, J. M., \& Modera, M. P. (2016). Do occupancy-responsive learning thermostats save energy? A field study in university residence halls. Energy and Buildings, 127, 469-478. https://doi.org/10.1016/j. enbuild.2016.05.024.

Reda, F., \& Laitinen, A. (2015). Different strategies for long term performance of SAGSHP to match residential energy requirements in a cold climate. Energy and Buildings, 86, 557-572. https://doi.org/10.1016/j.enbuild.2014.10.056.

Reda, F., Arcuri, N., Loiacono, P., \& Mazzeo, D. (2015a). Energy assessment of solar technologies coupled with a ground source heat pump system for residential energy supply in Southern European climates. Energy, 91, 294-305. https://doi.org/10.1016/j.energy.2015.08.040.

Reda, F., Tuominen, P., Hedman, Å., \& Ibrahim, M. G. E. (2015b). Low-energy residential buildings in New Borg El Arab: Simulation and survey based energy assessment. Energy and Buildings, 93, 65-82. https://doi.org/10.1016/j. enbuild.2015.02.021.

Reda, F., Karjalainen, S., \& Tuomisto, M. (2017). Combined use of nonintrusive monitoring techniques and energy recipes to reduce energy hungry behaviours. In 23RD ICE/ITMC.

Reddy, T. A. (2006). Literature review on calibration of building energy simulation programs: uses, problems, procedures, uncertainty, and tools. In ASHRAE transactions (p. Volume 112, Part 1). http://auroenergy.com/wp-content/uploads/2016 /05/2006_Reddy_ASHRAE-Trans_Literature-Review-onCalibration.pdf. Accessed 7 December 2017.

Regione Lombardia. (2015). Allegato B-Descrizione dell'edificio di riferimento e parametri di verificaDisposizioni in merito alla disciplina per l'efficienza energetica degli edifici e per il relativo attestato di prestazione energetica a seguito della DGR 3868 del 17.7.2015.

Ruivo, C. R., Ferreira, P. M., \& Vaz, D. C. (2013). Prediction of thermal load temperature difference values for the external envelope of rooms with setback and setup thermostats. Applied Thermal Engineering, 51(1), 980-987. https://doi. org/10.1016/j.applthermaleng.2012.11.005.

Soleimani-Mohseni, M., Nair, G., \& Hasselrot, R. (n.d.). Energy simulation for a high-rise building using IDA ICE: Investigations in different climates. https://doi.org/10.1007 /s12273-016-0300-9

Syed, A. (2012). Advanced building technologies for sustainability. John Wiley \& Sons, Inc.

Terrill, T. J., \& Rasmussen, B. P. (2016). An evaluation of HVAC energy usage and occupant comfort in religious facilities. Energy and Buildings, 128, 224-235. https://doi. org/10.1016/j.enbuild.2016.06.078.

Wang, L., \& Greenberg, S. (2015). Window operation and impacts on building energy consumption. Energy and Buildings, 92, 313-321. https://doi.org/10.1016/j.enbuild.2015.01.060.

Wang, Z., \& Wang, L. (2012). Buildings using CO2 predictive model, 133-138.

Wang, Z., Ji, Y., \& Ren, J. (2017). Thermal adaptation in overheated residential buildings in severe cold area in China. Energy and Buildings, 146, 322-332. https://doi. org/10.1016/j.enbuild.2017.04.053.

Yan, D., \& Hong, T. (edited by) (2018). Definition and simulation of occupant behavior in buildings. International Energy Agency, EBC Annex 66. Final report. 